\title{
„Der übernationale Gedanke der geistigen Einheit". Gottfried Salomon(-Delatour), der vergessene Soziologe der Verständigung
}

\author{
CHRISTOPH HENNING
}

Der in diesem Band verfolgten sozialen und biographischen Kontextualisierung von Soziologiegeschichte kann es dienlich sein, auch weniger bekannte Schicksale zu betrachten; Lebensläufe jener also, die auch Soziologen waren, die aber nicht oder nicht mehr im Rampenlicht der oft recht selektiv rezipierenden Gegenwart stehen. In solchen Lebensläufen wird das Typische einer Epoche häufig deutlicher sichtbar als in den erfolgsverwöhnten Lebensläufen berühmter Personen, die sich eher Extravaganzen und persönliche Eigenheiten leisten konnten. ${ }^{1}$

Eine interessante Figur für diese Art der Soziologiegeschichte des 20. Jahrhunderts ist Gottfried Salomon (1892-1964), der sich seit 1947 auch Salomon-Delatour nannte - und nicht mit dem Heidelberger Albert Salomon (1891-1966) zu verwechseln ist, der 1933 das Glück hatte, Professor an der „University in Exile“ an der New School for Social Research zu werden, und von dem gerade eine Gesamtausgabe in Arbeit ist. $^{2}$ Der folgende Beitrag behandelt Leben und Werk des bemerkenswerten Soziologen Gottfried Salomon, der in den soziologiegeschichtlich doch so beliebten 1920er Jahren ${ }^{3}$ einen hohen Bekanntheitsgrad hatte, heute dagegen kaum noch jemandem ein Begriff ist. ${ }^{4}$

Es gibt mehrere Gründe, sich für Gottfried Salomon zu interessieren. Der erste ist schlicht die Lücke der Forschung: in gängigen soziologi-

1 Vgl. Benjamin 1925, 238. Besonders wenn Autoren einem anderen Fach entstammen, bringen Biographien doch einmal Neues (Radkau 2005).

2 Zu Albert Salomon vgl. Gostman et al. 2005 sowie in diesem Band.

3 Siehe Berking 1984, Stölting 1986, Frisby 1989, Makropoulos 1991.

4 Näher zu Salomon bislang nur Rüegg 1964, Kambas 1982 und Belitz 1997. 
schen Geschichtsbüchern hat er kaum einen Platz - lediglich einige historische Studien nennen seinen Namen, aber auch wenig mehr als das. ${ }^{5}$ Zweitens stellt Gottfried Salomon für die Tradition der Soziologie ein wichtiges Bindeglied dar: einerseits ist er ein direkter Schüler von „Klassikern“ wie Ernst Troeltsch, bei dem er in Berlin hörte; Georg Simmel, bei dem er in Straßburg promovierte; und Franz Oppenheimer, bei dem er habilitierte und dessen Assistent er für 8 Jahre war. Zu seinen Frankfurter Studenten der 1920er Jahre hingegen gehörten solch illustre Gestalten wie Theodor Wiesengrund und Walter Benjamin. Auch seine zweite Frankfurter Lehrzeit der späten 1950er und frühen 1960er Jahre dürfte einige Soziologiestudenten beeinflusst haben. Das wiegt umso schwerer, als er nach vielfachen Zeugnissen mündlich überzeugender war als schriftlich. Drittens hat er in den 1920er Jahren eine interkulturelle und „überstaatliche“ Idee von Soziologie praktiziert (und zwar mehr praktiziert als reflektiert), die heute zwar weniger ungewöhnlich ist, damals jedoch erst erkämpft werden musste. Diese Soziologie eignete sich nicht dazu, im Rahmen nationalistischer Werturteile einer deutschen „Selbstbehauptung“ zuzuarbeiten (Heidegger 1983, cf. Rammstedt 1986, Klingemann 1996). Im Gegenteil, eben solchen Katastrophen wollte sie vorbeugen. Im Rahmen dieser Bemühungen hat Salomon mit den meisten wichtigen Geistern seiner Zeit korrespondiert; jedenfalls solange, bis 1933 das Gespräch abbrach. Und letztens finden sich in seinen manchmal recht trockenen Werken Positionen, die sehr modern oder sogar postmodern sind, da sie mit damaligen Mitteln eine positive Theorie der Einheit in der Differenz zu formulieren suchen.

Im Folgenden werden die Inhalte des soziologischen Werkes von Gottfried Salomon in Grundzügen so weit wie möglich entstehungsgeschichtlich gedeutet. ${ }^{6}$ Dazu werden die einzelnen Stationen seines Wir-

5 Salomon wird geführt, teilweise mit inkorrekten Angaben, in Bernsdorf 1980, 477; Kaesler 1983, 379 f. (der ihn als „Juden“ am „Äußere[n] Rand“ der Soziologie verortet, 43); Hammerstein 1989, 133f.; Heuer 1997, 328330; Schefold 2004, 125, 651; Kaesler 2005; kursorisch in Wittebur 1991 und DB 1993. Stölting 1986, 173-175 geht kurz auf das Jahrbuch für Soziologie ein. Rammstedt (1969, 1991, 1994) hat wichtige Fragmente Salomons publiziert.

6 Für ihre Kooperation danke ich dem Universitätsarchiv Frankfurt am Main (UAF), dem Bibliotheksarchiv Frankfurt (BAF), dem Exilarchiv der deutschen Bibliothek Frankfurt, dem International Institute for Social History in Amsterdam (IISH, wo der Nachlass bis 1933 liegt) sowie der Manuscript Division der New York Public Library Hilfe. Einige Dokumente wie das Manuskript einer Autobiographie und die Bestände der Dokumentationsbibliothek Davos konnten nicht berücksichtigt werden, was die vorliegenden Zeilen zu vorläufigen macht. Für Hinweise und Kommentare danke ich Otthein Rammstedt, Günther Roth und Stephan Moebius. 
kens - Straßburg, Berlin, Frankfurt, Davos, Paris, die Vereinigten Staaten und wieder Frankfurt - vorgestellt. Auf die Vorläufigkeit dieses Portraits sei dabei hingewiesen.

\section{Biographische Skizze}

„Der Wissenschaftler muss die Rolle des Außenseiters annehmen." Salomon 1931, 160

Gottfried Salomon lebte in Deutschland, Italien, Frankreich, den Vereinigten Staaten und wieder in Deutschland. Schon dies vermittelt einen rastlosen Eindruck, was allerdings keinen Rückschluss auf seinen Charakter zulässt, da es auch die Zeitumstände waren, die ihm eine langfristige Etablierung zeitlebens verwehrt haben. ${ }^{7}$ Die wissenschaftlich bedeutendsten Jahre seines Lebens verbrachte er in Frankfurt; erst als Assistent Franz Oppenheimers (1921-1929); dann unter Karl Mannheim, der ihn als Vorgesetzter allerdings eher duldete und dem Salomon dann aus dem Weg ging (etwa, indem er in der Schweiz die Davoser Ferienkurse organisierte); und schließlich, wenn auch erneut eher geduldet denn willkommen, erneut als Remigrant, von 1958 bis zu seinem Tode 1964.

Beim Machtantritt Hitlers befindet er sich zu einem Gastaufenthalt in Italien und blieb auf Anraten offizieller Stellen auch dort. 1933 bis 1940 lebte er, teilweise unter großer Gefahr, in Frankreich - er betätigte sich in jener Zeit allerdings nur begrenzt als akademischer Soziologe, sondern arbeitete u.a. für das Außenministerium als Berater in deutschen Angelegenheiten. Das verhielt sich nach endlich gelungener Flucht in die Vereinigten Staaten Anfang 1941 auch dort ähnlich: Salomon erhielt zwar zunächst ein Stipendium von der Rockefeller Foundation und war für zwei Jahre Gastprofessor an der New School; tritt aber kaum mit Schriften in Erscheinung, sondern ist eher organisatorisch tätig - während des Krieges etwa für die Regierung, nach 1945 erarbeitet er sozialwissenschaftliche Curricula für einige Hochschulen. ${ }^{8}$

7 Zu den Stereotypisierungen des „Jüdischen“ jener Zeit gehörte das „Rastlose“ (Sombart 1911, 323f.; mit Anklängen an Ahasver, den ewigen Wanderer). Von ferne klingt das noch in der Titulierung als „Grenzgänger“ an (Mülder 1985, Belitz 1997a - siehe unten zu Rüegg 1964).

8 Bernsdorf 1980, 368 gibt an: „1932 Austausch-Prof. in Rom; 1933 Emigration nach Frankreich, dort seit $1933 \mathrm{Hg}$. der Information Economique; 1934-40 Wirtschaftsexperte für Zentraleuropa und Lehrbeauftragter an der Univ. Paris; 1941 Flucht nach den USA; 1941-43 Prof. an der New School for Social Research in New York; 1942 an der Univ. Denver, Gründung des Instituts für Internationale Studien; während des Krieges Berater des War Department in Washington; 1946-50 Prof. der Soziologie an der Co- 
Nach einigen juristischen Auseinandersetzungen lehrte er ab 1958 wieder in Frankfurt, jedoch erneut ohne Anbindung. Abschlussarbeiten etwa konnte er nur mit schriftlicher Einzel-Erlaubnis des Dekans abnehmen. ${ }^{9}$ Akademisch blieb er also stets ein Außenseiter. Zeitlebens bedauerte er, kein opus magnum verfasst zu haben; dieses erschien erst postum (Salomon 1965). ${ }^{10}$ Auch hatte er nie eine reguläre Position als ordentlicher Professor inne. Dafür war das Fehlen eines großen Werkes nur ein Grund. Auch seine sozialistische, wenn auch nicht marxistische Haltung Anfang der 1920er Jahre und seine Herkunft mögen eine Rolle gespielt haben. Salomon machte sich stattdessen als Herausgeber einflussreicher soziologischer Sammlungen und als Organisator intellektueller Happenings einen Namen - darunter die berühmten Jahrbücher für Soziologie und die Davoser Gespräche, bei denen u.a. Ernst Cassirer und Martin Heidegger aufeinander prallten. Diese organisatorische und dialogische Anlage mag ein Grund für seine Vergessenheit bei Späteren sein; wenn auch kein guter. Die Vergessenheit ist umso seltsamer, als sich sein Lebenslauf mit unzähligen bekannten Figuren verbindet.

\section{Begegnung und Parallele: Siegfried Kracauer}

Geboren wurde Gottfried Salomon am 21. November 1892 in Frankfurt am Main, im gleichen Jahr wie Walter Benjamin und Helmut Plessner, als Sohn eines jüdischen „Fabrikanten“ und einer französischen Hugenottin. ${ }^{11}$ Das französische Erbteil hat er ein Leben lang kultiviert; so wurde er Vorsitzender der Deutsch-Französischen Gesellschaft, lehrte

lumbia Univ., in Michigan (Ann Arbor) und Illinois (Urbana); Aufbau eines Graduate Department an der Yeshira [!] Univ. und am Hunter College New York; seit 1958 in Frankfurt a.M.“ (368f.). Die Archive von Columbia-University, Hunter-College und Yeshiva-University gaben auf Anfrage an, keine Unterlagen zu besitzen.

9 Der Dekan der philosophischen Fakultät schreibt 1963: man sei in Bezug auf Salomons Beteiligung an Diplom- und Doktorprüfungen so verblieben, „dass jeder Fall einzeln dem Dekan vorgelegt und von diesem entschieden werden sollte“ (Rektoratsakte UAF, Abt 4, Nr. 134, Kraft an Adorno, 23.11. 1963).

10 Oppenheimer schreibt Salomon am 1.7.1929: „Hätte ich länger bleiben können, so hätten sie Zeit gehabt, die große Arbeit zu schreiben, auf die Ihre Freunde schon so lange warten“ (IISH, IIb/866). Das Buch von 1965 greift dann auf trotz Kürzung über $600 \mathrm{~S}$. auf bereits Gedrucktes zurück.

11 Karlfried Gründer (1988, 92) gibt eine Selbstbeschreibung Salomons wieder: „väterlicherseits ein Cohen, mütterlicherseits Nachfahre eines Mordbrenners, des Marschalls Turenne“. Der Lebenslauf der Dissertation sagt: „Sohn des Fabrikanten Hermann Salomon in Frankfurt a. M.“ (1916, 100). 
und schrieb über Frankreich und gab französische Werke auf deutsch heraus (z.B. Saint-Simon, Proudhon, Worms und Sorel; cf. Belitz 1997a). Den Mädchennamen der französischen Mutter, Delatour, nahm er erst recht spät, nämlich im amerikanischen Exil seit 1947 an - ähnlich wie Theodor Wiesengrund, der sich erst seit 1943 Adorno nannte. ${ }^{12}$ Er schrieb sich auch De la Tour (in: Gassen 1958, 291) und nannte sich in Frankreich aus Schutzgründen zeitweise Godefroy. Im besetzten Frankreich wechselte er häufig die Postadresse, da er politisch aktiv war.

In Frankfurt wuchs Salomon in der Bäckerstraße nahe der heute bekannten Berger Straße auf. ${ }^{13}$ Hier begegnet sogleich ein denkwürdiges Detail: Einige Hauser weiter nämlich wohnte seit 1904 auch Siegfried Kracauer (1889-1966; Belke 1989, 5), zu dem es allerdings wenige nachweisbare Beziehungen gibt. ${ }^{14}$ Salomons besuchte die Musterschule im Frankfurter Nordend - ein damals bekanntes Reformgymnasium, auf dessen Besuch er stolz war; Kracauer besuchte währenddessen das Philantropin, ein Reform-Realgymnasium der israelitischen Gemeinde, und anschließend die Klinger-Oberrealschule.

Kracauers Lebenslauf weist allerdings deutliche Parallelen zu demjenigen Salomons auf: geboren in derselben Stadt, bewegen sie sich weiterhin in einem ähnlichen Umfeld. Georg Simmel, der Doktorvater Salomons, lud Kracauer 1917 ein, bei ihm in Straßburg zu promovieren, was dieser jedoch nicht wahrnahm - wohl auch, weil er bereits als Architekt promoviert war (Frisby 1989, 236). Kracauer wie Simmel waren später der Frankfurter Soziologie verbunden: 1921 habilitiert sich Salomon bei Franz Oppenheimer für Soziologie, 1922 tritt Siegfried Kracauer mit einem Buch über Soziologie als Wissenschaft an die Öffentlichkeit, das stark von Georg Simmel und einer religiösen Herangehensweise geprägt ist. Das Thema des „Glaubens“15 zieht sich seit der Doktorarbeit auch durch das Lebenswerk von Salomon (1938, 174; 1959, V). Auch die distanzierte Nähe zu Marx teilen beide (Frisby 1986, 125).

Beide arbeiten ebenfalls schon früh in einer gewissen Distanz zum normalen Lehrbetrieb - Kracauer ist ausgebildeter Architekt und arbeitet

12 Rammstedt 1969, 221 (und nicht 1933, wie Käsler 2005 will). Möglicherweise wollte sich Gottfried Salomon von seinem Namensvetter Albert absetzen, der damals ebenfalls in New York lehrte.

13 Zur Frankfurter Soziogeographie siehe Schivelbusch 1985, Schütte 1999.

14 Diesen Hinweis verdanke ich Otthein Rammstedt (cf. 1994, 168). In Amsterdam gibt es zwei Briefe Kracauers an Salomon von 1921 (IISH, Gottfried Salomon-Delatour Papers, IIb/631). In Briefen Benjamins an Kracauer taucht Salomon nur am Rande auf, in Frankfurt wie in Paris.

15 „Vor allen Dingen lagen die wichtigsten Gemütsbedürfnisse, die religiösen, brach: es gab keinen lebendigen allgemein verpflichtenden Glauben, der unserem Wesen entsprach“, so Kracauer (1915, 15; Frisby 1986, 120). 
als Feuilletonist der Frankfurter Zeitung, Salomon sucht zumindest in den späten 1920er Jahren Kontakte eher außerhalb der Frankfurter Universität; möglicherweise, weil er auf eine Festanstellung in der Nachfolge Oppenheimers gerechnet hatte, die dann aber Karl Mannheim erhielt. Auch gehen beide nach 1933 für einige Jahre ins Exil nach Frankreich, bevor sie 1941, nach einigen Schwierigkeiten, in die USA weiter fliehen. ${ }^{16}$ In den USA haben sich beide allerdings - wie viele andere Emigranten - nie wirklich etabliert; auch Kracauer erhielt ja nie eine feste Anstellung. Sie haben hier aus einer eher fragilen Position ihre Theorien formuliert. Über ihr Verhältnis - wenn es denn eines gab - ist wenig auszumachen. ${ }^{17}$ Es gibt allerdings einige frühe Rezensionen, in denen Kracauer Salomons Jahrbuch für Soziologie in hohen Tönen lobt:

„Wiederum ist der Herausgeber, Prof. Gottfried Salomon (Frankfurt), bemüht gewesen, eine Reihe führender Autoren aus verschiedenen Nationen zu vereinen. Er hat sich mit dem Jahrbuch unstreitig das Verdienst der Schaffung eines Forums erworben, auf dem sich die Autoren zwar nicht zu einer ,Gemeinschaft‘ im Sinne Tönnies, zusammenfinden, aber doch gesellschaftlich miteinander Fühlung aufnehmen“ (Kracauer 1926, $371 \mathrm{f.}$.). ${ }^{18}$

\section{Dissertation bei Georg Simmel in Straßburg}

Wir haben hiermit vorgegriffen. Zunächst besuchte Salomon ab 1909 die Universität in München, wo er Kunstgeschichte studierte (Rammstedt 1969, 221). Das Interesse für Kunstgeschichte teilt er mit Karl Mannheim, dessen spätere Wissenssoziologie methodisch stark auf Erkenntnissen Alois Riegls und Erwin Panofskys basierte (Barboza 2005).

16 Kracauer soll gesagt haben, er verhungere lieber in Paris, als Geld von Horkheimer anzunehmen (Hinweis von G. Roth; vgl. Frisby 1989, 234). Zu Kracauer Mülder 1985; Jay 1986, 152-236; Belke 1989; Frisby 1989.

17 In Amsterdam gibt es zwei kleine Briefe Kracauers an Salomon von 1921, in denen man sich im Cafe Westend verabredet, um sich persönlich kennen zu lernen (IISH, IIb/631, 30.6.1921). Mittelsfrau war Gertrud Kantorowizc.

18 Kracauer, der die anderen Beiträger des zweiten Bandes bis auf Karl Mannheim eher zerreißt, urteilt über Salomons Aufsatz: „Der Herausgeber Prof. Salomon selber deckt in einem auch durch seine Materialkenntnis fesselnden Aufsatz die Abhängigkeit Marxens von dem französischen Empirismus und Sensualismus auf, die sich aus der Genesis etlicher Grundbegriffe ergibt“ (1926, 374; vgl. Mülder 1985, 170). Salomon war seit 1925 außerordentlicher Professor, was von der sozialen Lage her noch immer dem entsprach, was Kracauer bereits 1923 beklagt hatte: die miserable Lage der Frankfurter Privatdozenten. Kracauer hat auch Bände 1 und 3 des Jahrbuchs rezensiert (Frankfurter Zeitung, 3.1.1926; 25.9.1927; Kracauer 1926, 374, Fußnote). 
Ab 1911 studierte er Naturwissenschaften und Physiologie in Heidelberg, damals ein „Schnittpunkt intellektueller Kreise“ (Treiber 1995, Blomert 1999). Später schrieb er sich mit Georg „von“ Lukács, als der in Heidelberg war. $^{19}$ Die naturwissenschaftliche Ausbildung teilt er mit Generationsgenossen wie Helmuth Plessner oder Norbert Elias, später ebenfalls Assistent bei Mannheim. In dieser Zeit tritt Salomon allerdings außer in einigen Gedichten noch nicht publizistisch in Erscheinung.

Die nächste aktenkundige Eintragung ist die philosophische Promotion in Straßburg bei Georg Simmel im Jahre 1916, mit 24 Jahren. Simmel hatte nach langer Zeit als Privatdozent, in der er zahlreiche Anfeindungen hatte ertragen müssen, soeben eine Anstellung als Professor in Straßburg erhalten, und zu ihm ging Salomon. ${ }^{20}$ Dahinter stand vermutlich ein Druck aus der Familie, da sein Vater auf einen zügigen Abschluss des Studiums drängte. Ein Freund der Familie hatte Salomon auf Georg Simmel hingewiesen, bei dem eine Promotion gut und schnell machbar wäre. ${ }^{21}$ Obwohl das verlockend klang, war Salomon zusammen mit der früh verstorbenen Philosophin Betty Heimann (geb. 1885 in Hamburg und ebenfalls jüdischer Abstammung) der einzige Doktorand Simmels, der bereits 1918 verstarb (Kracauer hatte dieses Angebot ja abgelehnt). Simmel musste den jungen Salomon zugleich bremsen (ursprünglich wollte er die ganze deutsche Mystik portraitieren) und antreiben (Salomon verlangte mehrfach Aufschub). ${ }^{22}$ In seiner 1916 veröffent-

19 „Sehr geehrter Herr von Lukács! Seit ich ,Von der Armut am Geiste“ las, haben ich den innigen Wunsch gehabt, Sie persönlich zu kennen, in dem Glauben, dass gemeinsame Liebe vereinigt (Philippe, Kassner, Kierkegaard). Am 16. Juli soll ich in Heidelberg in der soziologischen G. sprechen (,Typologie des Religiösen'), ich würde Ihnen darum gerne, da ich Ihre Hinneigung zur Mystik fühle, gewissermaßen eine Vorlesung oder Vorbesprechung halten, nur weil ich weiß, dass man derart am schnellsten sich annähert [...] Ich kann offen sagen, dass ich Sie zu denen zähle, dich ich am höchsten schätze“ (Brief an Lukács, 3.7.1914, in: Karadi 1982, 338). Ernst Bloch schreibt Salomon 1914: „Sehr geehrter Herr Salomon! Ich habe [...] durch Dr. von Lukács von Ihnen gehört und freue mich auf ihren Besuch“ (IISH, Gottfried Salomon-Delatour Papers, IIb/128). Der frühe Briefwechsel Salomons enthält allerdings kaum theoretische Einsichten. So schreibt Lukács an Salomon: „Wenn sie Prof. Simmel sehen, grüßen Sie ihn von mir“ (28.4.1915, IISH, IIb/721). In seiner Dissertation nennt Salomon als Lehrer neben Simmel: „Wölfflin, Burger, Windelband, Driesch, Tröltsch, Brentano, Weber“" (Salomon 1916, 100).

20 Es gibt von ihm eine Vorlesungsmitschrift von Simmel (Rammstedt 1969).

21 „Kurz vor dem ersten Weltkrieg empfahl mich Wichert von der Mannheimer Kunsthalle an den gerade ernannten Philosophen, bei dem man kein ianer (Kantianer, Husserlianer usw.) zu sein brauchte, vielmehr in seinem Eigenen angeleitet werde“ (Salomon 1958, 291; cf. Rammstedt 1969, 221).

22 Siehe Rammstedt 1994, Salomon in Gassen 1958. 
lichten Arbeit behandelte er dann die „theologia deutsch“, einen Text aus dem 15. Jahrhundert, der schon für Martin Luther und noch für Martin Heidegger bedeutsam war. Es handelt sich, ganz ähnlich wie beim jungen Heidegger, um eine Anwendung von Simmels Lebensphilosophie und Religionssoziologie auf die Philosophie des Mittelalters. ${ }^{23}$

Die Mystik war Anfang des 20. Jahrhunderts bei vielen kulturkritischen Intellektuellen von großer Anziehungskraft: nicht nur Karl Mannheim und Georg Lukacs lasen Meister Eckhart, auch Gustav Landauer, Martin Buber und viele andere beschäftigten sich damit, meist im Sinne einer ganzheitlich gestimmten Kulturkritik an der mechanisierten und atomisierten Moderne. Auch Ernst Troeltsch, Max Weber und Georg Simmel hatten sich ihr gewidmet. ${ }^{24}$ Doch keineswegs nur progressive Geister waren davon angetan - die „deutsche Mystik“ war zugleich Tummelplatz und Projektionsfläche für rassistisch-antisemitische „völkische Revolutionäre“ (Ziege 2002). ${ }^{25}$ Sie war also politisch aufgeladen.

Was war es nun, das der junge Salomon unter Simmel aus der theologia deutsch extrahierte? Bereits die allererste Veröffentlichung Gottfried Salomons, ein kleines Gedicht in der modernistischen Wochenzeitung Die Aktion, thematisierte eine mystische „Ekstase“ (Salomon 1914, cf. Peter 1982). Schon dort wird ein Erleben hymnisch gepriesen, das sich in Worten nicht wiedergeben lässt. ${ }^{26}$

23 Martin Heidegger habilitierte sich 1916 über Duns Scotus bzw. Thomas von Erfurt (Gudopp 1983, 41-75; Rentsch 1989, 36-54).

24 Beim Ersten Deutschen Soziologentag von 1910 gab es folgenden Disput (nach Simmel 2005, 89 ff.; siehe DGS 1911, 204 ff.): (Simmel:) „Hat das Christentum [...] überhaupt eine soziale Bedeutung?“ (89); „alles, was es überhaupt an Idealen gibt - das sozialistische, das konservative, das individualistische, das anarchische [...] - alle sind christlich! [...] Sind denn das alles Fälscher? Nein, [...] das sind die relativen Gestaltungen, die es allein im Soziologischen gibt“ (92). (Max Weber:) „Also alles, was Simmel sagt, für den Sinn der religiösen Motive zugegeben, so muss vom Standpunkt der Soziologie doch stets die psychologische Frage gestellt werden, und sie ist [...] von allen Seiten, auch den [...] höchsten Formen der Mystik gestellt worden: wie, durch welches Medium, wird der Einzelne seiner Beziehung zum Ewigen gewiß?“ (Simmel:) „Ratio!“ (94). (Troeltsch:) „Ich möchte aber sagen: was er [Simmel, $\mathrm{CH}$ ] gesagt hat, ist eigentlich nichts anderes als eine Illustration meines dritten Typus, der Mystik gewesen. Für die Mystik trifft das alles zu“. (Simmel:) „Das habe ich vergessen!“ (95). Diese Ausführungen finden sich in DGS 1911, 172-174.

25 Der Verfasser einer der Quellen, die Salomon 1916 zitiert (Schwarz 1913, siehe Schwarz 1920), bekam 1910 den Lehrstuhl für Philosophie in Greifswald, auf den auch Simmel eine gute Chance hatte - man darf also auf Bekanntheit schließen. Später verfasste er eine „transzendentale Grundlegung“ des Nationalsozialismus (Schwarz 1933, siehe Henning 2001).

26 „Die Glieder meines Leibes / sind mir fremd und fern / wie irgend Ding und wie ein Kind. / Ich fühl den Geist wie Angebind, / wie eine Frucht, 
Eben dies macht Salomons Dissertation nun zum Thema, indem aus dieser Unsagbarkeit der Gegensatz von zwei „Grundverhalten“ (1916, Vorwort) abgeleitet wird. Auf der einen Seite steht das „Erleben“ der Mystik (1916, 6; ein Terminus, der auf den Vitalismus Hans Drieschs wie auf Wilhelm Diltheys Hermeneutik zurückverweist), in dem Erlebender und Erlebtes, Gott und Seele, als „Einheit“ und Ganzheit erlebt werden (das Wort „Einheit“ fällt allein auf S. 6 f. elfmal). Das Problem ist nur: „Das mystische Erleben ist stumm und namenlos, es kann nicht recht ausgesagt werden“ $(1916,10)$. Es ist damit instabil. Ihm gegenüber steht der Glaube (1916, 22-35), Kennzeichen des Protestantismus, in dem - gut Hegelianisch - die zum Ausdruck gebrachten Gehalte des religiösen Erlebnisses in ihrer Positivität oder „Form“ der „Seele“ als fremd gegenüberstehen können. Dieser Simmelsche Topos der „Tragödie der Kultur“" war damals recht gängig (Simmel 1904, Lukács 1911).

Die „Grundverhalten“, die Salomon als Unterscheidungsmerkmal heranträgt, sind die eher passivische Rezeption beim Glauben (Gnade kann hier nur erhofft, nicht erwirkt werden, 1916, 25 f.), und die eher aktivische Öffnung bei der Mystik. Inhaltlich war die These mutig, hatte doch Max Weber genau umgekehrt in der Mystik eine „negative Wirkung auf das Handeln“ gesehen. ${ }^{27}$ Bei Salomon wird sie nun zu einem sozialen Aktivator: „So hat die Nachfolge zwei Motive, den Gehorsam gegen Christus und den Dienst in der Gemeinschaft“ (1916, 70). Ganz ähnlich argumentierte später auch Karl Mannheim (1929, 184ff.). ${ }^{28}$

Vor dieser Unterscheidung kennzeichnet Salomon die theologia deutsch als immanent bleibende Schrift, die konfessionell wie soziologisch eher neutral ist, da es primär um das religiöse „Grundverhalten“

und meinen Willen / wie einen Kern. / So wie ein Weib sich selbst nicht weiß / und untreu wird, bin ich ergrimmt / und prahlend an das Wort gebunden, / so weltverloren wie ein Greis. / So wie ein Freund mir mein Erlebnis trübt, / das ich weit über ihn hinaus geliebt, / ist alles Wort, das mich bestimmt und mächtig meint, / das Leben selber sei in Ewigkeit / für meine kleine, kleine Zeit gefunden“ (Salomon 1914; vgl. Buber 1909a, 1909b).

27 „Nichthandeln, in letzter Konsequenz Nichtdenken [...] sind der Weg, denjenigen inneren Zustand zu erreichen, das als Besitz des Göttlichen, als unio mystica mit ihm genossen wird“ (Weber 1922, 330). Für Troeltsch ist Mystik „radikaler, gemeinschaftsloser Individualismus“ (DGS 1911, 174).

28 Beide deuten Mystik als Aktivismus und Rationalismus als ihr Surrogat: „Wo die Situation dem politischen Angriff entgegenreifte (in Frankreich etwa), dort nahm die ideenhafte Utopie dezisiv scharf konturierte rationale Gestalt an; wo dieser Weg ungangbar wurde, wie etwa in Deutschland, erfolgte eine Verinnerlichung“ (Mannheim 1929, 191). An Levy-Bruhl, der später in Davos war, lobt Salomon, er habe „die Mystik als ursprüngliches und niemals ganz eliminiertes Denken erklärt“ (in: Herlitz 1927 III, 1086). 
geht. ${ }^{29}$ Die vielleicht ungewollte Konsequenz ist allerdings eine Stärkung des Subjektes („Das Gottesverhältnis wird ein Persönlichkeitsverhältnis“, 47). In alledem lässt sich nicht verkennen, wie Salomon stark in Richtung Mystik lehnt, die er ein „existenziales Verhalten“ nennt (1916, 2; lange vor Heidegger hier eine Rezeption Kierkegaards).

Werkgeschichtlich war insbesondere die Dialektik der „Einheit“ prägend: sie stellt in Form einer friedlichen Inklusion aller Menschen auch in späteren Werken ein Ziel da; nur weiß Salomon schon aus seinem Frühwerk, dass jeder Versuch, diese Einheit ausdrücklich zu machen, theoretisch oder politisch festzuschnüren, ein „verdinglichtes“ (1916, 87) Verfallen in die „Gegenständlichkeit“ (23) und somit eine Entfremdung bedeuten kann (siehe Henning 2001a). Diese „Formen“ wird er in späteren Werken oft kritisieren, wenn auch in anderen Kontexten und unter anderen Titeln (wie denen des Nationalismus und Organizismus).

Eine Schwäche der Darstellung ist es, dass die eigentlich soziologischen Botschaften kaum an die Oberfläche treten: einerseits das Paradox von Persönlichkeit und Gemeinschaft als Effekt der christlichen „Nachfolge“ “ ${ }^{30}$ andererseits die aktivierende Auswirkungen der Mystik. Salomon, der sich zeitlebens als Schüler nicht nur von Simmel und Oppenheimer, sondern auch von Ernst Troeltsch fühlte, gelingt es nur selten, Max Webers Frage nach den weltlich-sozialen Auswirkungen spezifischer Glaubensgehalte im Hinblick auf die theologia deutsch transparent zu beantworten - erkennbare Thesen dazu ${ }^{31}$ gehen, wie in einigen seiner Texte, in einer Fülle von aufbereitetem Material etwas unter. ${ }^{32}$ Vielleicht fand Salomon deswegen in Georg Simmel keinen wirklichen Förderer.

29 „Wie die Mystik eine Reform der Lehre geben will, so will das Traktat eine Reform des christlichen Lebens anbahnen [...], ohne eigentlich[en] häretischen oder revolutionären Absichten. Die ,Religion“ als die Objektivation der religiösen Inhalte wird kaum berührt, ausschließlich im Hinblick auf das religiöse Subjekt wird das Thema ,Gott und der Mensch' betrachtet“ $(1916,96)$.

30 „Das Paradox ist, dass das Ethos, das Ethos zu Gott ist, sich durch den Nächsten zu Gott wendet; dass der Einzelne sich durch die Gemeinschaft hindurch nach Christi richten [...] soll“ (Salomon 1916, 61).

31 „In der Konsequenz des Gehorsamkeitsgedankens also liegt die ethische Rückwirkung und Ausgestaltung des Glaubens im Dienst, der sozialen Wirksamkeit“" (Salomon 1916, 73).

32 Manche Aussage über Salomon klingt ähnlich. Oppenheimer schreibt Salomon am 30.12.1920: „Ihre Einleitung zu Proudhon war mir, ehrlich gesagt, ein wenig zu chaotisch“ (IISH, IIb/866). Nach Salomons erster Zeit in Frankreich 1927 sagt Werner Picht über Salomon: „mais quelque peu brouillon, d'un judgment pas toujours sur et d'un extreme agitation“ (nach Belitz 1997, 293). 


\section{In Berlin bei Walter Rathenau}

„In den Jugendjahren eines jeden deutschen Juden gibt es einen schmerzlichen Augenblick, an den er sich zeitlebens erinnert: wenn ihm zum ersten Mal voll bewusst wird, dass er als Bürger zweiter Klasse in die Welt getreten ist und dass keine Tüchtigkeit und kein Verdienst ihn aus dieser Lage befreien kann.“ Rathenau 1911, S. 188 f.

Nach seiner Dissertation wollte Salomon zu Walter Rathenau. Dafür konnte er nicht auf Vermittlung Simmels rechnen. ${ }^{33}$ Etwas später finden wir Gottfried Salomon dennoch in Berlin. Sein Vater verstarb und Salomon übte einen bürgerlichen Beruf aus. Er war ein Jahr bei der AEG, die unter Walter Rathenau im Weltkrieg zu Höchstleistungen auflief. Zuständig war er hier u.a. für eine „Holoryth-Maschine“, dem Vorläufer des Computers. In die Organisationsprinzipien der „modernen Gesellschaft“ erhielt Gottried Salomon damit - im Unterschied zu manchen anderen Soziologen - einen auch praktischen Einblick. Danach leistete er ein weiteres Jahr zivilen Militärdienst ab. ${ }^{34}$ Wie tief der Kontakt mit Walter Rathenau auch gewesen sein mag, ein Einfluss seiner Mechanismuskritik ist nach dem Ersten Weltkrieg unverkennbar. ${ }^{35}$

Während dieser Zeit in Berlin hörte er auch bei Ernst Troeltsch. ${ }^{36}$ Salomon hat - besonders seit Simmel verstorben war - ausgestattet mit dem „kulturellen Kapital“ eines Simmelschüler - Zugang zu einflussreichen Kreisen erlangt, etwa zu Verlagen oder Autoren. So finden wir ihn nach dem Ersten Weltkrieg als rührigen Herausgeber, etwa in Martin Bubers Zeitschrift „Der Jude“, und als Verleger, so bei Paul Cassirer oder dem Verlag „Drei Masken“. Einige Projekte wie eine Neuausgabe Simmels scheiterten (in diesem Fall am Widerstand der Witwe). ${ }^{37}$

33 Simmel schreibt Salomon am 19.2.1917, er könne ihn nicht an Rathenau vermitteln (IISH, IIb/1078). Salomon wird von Michael Landmann nicht als Simmelschüler geführt (Rammstedt 1969, 221; vgl. 1991, 1994).

34 Erneut nach O. Rammstedt (mündlich). Laut Rüegg (1964, 625) war er „ein Jahr als Leiter der statistischen Abteilung in Oberschöneweide tätig. 1918 kam er in die statistische Abteilung der Reichsbekleidungskammer“.

35 „Das Leben ist mechanisiert und bloß funktionell“ (Salomon 1920, 341; vgl. Rathenau 1912, zur soziologischen Rezeption Rathenaus Schulin 1977, Kleinsorg 1992; vgl. W. Brenner 2005). Ein Lebenslauf von 1940 aus der New York Public Library gibt an: „He was at one time confidential secretary to Walter Rathenau“ (Manuscript Division, Emergency Committee Records, box 91).

36 In Troeltschbiographien (Drescher 1991) taucht Salomon nicht auf, doch es gibt zwei erhaltene Briefe von Troeltsch von 1918/19 (IISH, IIb/1179).

37 Dies ist aus dem Briefwechsel in Amsterdam zu erschließen. Ernst Cassirer vermittelte Salomon schon 1919; Buber selbst lädt Salomon 1920 ein, für 
Bei alledem radikalisierte er sich politisch zusehends - so hielt er Privatvorlesungen über die russische Revolution (Rüegg 1964, 625). Ein Aufsatz von 1920 namens „Osten und Westen“, inhaltlich vergleichbar der Schrift Europa und Asien von Theodor Lessing (1918) und in vielem angelehnt an Oswald Spengler, schlägt noch recht spekulative Töne an. Werkgeschichtlich eine Art Gelenk zwischen den frühen Gedichten und der wenig später einsetzenden diszipliniert theoretischen Arbeit, transformiert dieser Aufsatz die mystischen Einheitsvorstellungen der Dissertation ins Politische. Salomon hofft: „die Menschheit wird am Ende eine konkrete und reale Gemeinschaft bilden“ (1920, 338; eine „letzte Einheit“، 337). Dem stünde nur noch ein präfinaler Dualismus entgegen: „Die Erde ist ganz entdeckt, aber in eine Zweiheit der Kulturwelten zerteilt“ (1920, 339); nämlich in die von Osten und Westen.

Der Westen („Amerika!“, 343) krankt an einer „protestantischen Entseelung“ (345) durch die „Europäisierung der Erde“ (338; „westeuropäische Destruktion“, 342). „Die östliche Menschheit“ hingegen (340) - genannt werden China und Indien (344), auch das revolutionäre Russland und die von deutschen Juden soeben als Vorbild entdeckt Ostjuden scheinen durch $^{38}$ - wird demgegenüber als „seelenhaft“ vorgestellt: „Der Westen wird im Osten sein Vorbild sehen, denn der Osten besitzt die sozial- und wirtschaftsethischen Fonds, ohne die keine Gemeinschaft Bestand hat“" (Salomon 1920, 340).

Dieser kleine Text hat eine religiöse Schlagseite: Da die Religion die „eigentlich gemeinschaftsbildende Kraft“ sei (1920, 346; ein Einfluss von Troeltsch und Buber, vielleicht auch von Durkheim, den Salomon später ebenfalls übersetzt herausgeben wollte), fordert Salomon die „definitive religiöse Einheit, eine Universalreligion“ (346). Diese Forderung entspricht dem Geist der Zeit, der auf der Suche nach „Weltanschauung“ war (Bry 1924; s.o., Fn. 15). Verstörend wirken indes die merkwürdige Konfessionslosigkeit wie auch die Instrumentalisierung der Religion, die erst noch „gebildet“ (346) werden soll; etwas, was Mannheims Schüler Alfred Seidel (1924) „Kulturgewolle“ nannte.

Wie würde eine solche Weltreligion wohl mit den älteren Kirchen, wie mit dem Judentum umgehen? Der „katholische Atheismus“ Saint-

den Juden soziologische Literatur zu besprechen; „Frau Professor Simmel“ lehnt 1926 ein Vorwort Salomons zu Simmels Socialer Differenzierung ab.

38 Martin Buber „ordnete das Judentum zusammen mit der indischen, chinesischen und nahöstlichen Kultur dem asiatischen Geist zu und setzte diesen der westlichen Zivilisation entgegen“ (Brenner 2000, 151; vgl. Buber 1916, 9-48; Katz 1993a). Schon Webers Übertragung des Paria-Begriffes auf das antike Judentum ging in diese Richtung. Eine wichtige jüdische Zeitschrift (1901-1923) nannte sich Ost und West (Brenner 2001, 39). 
Simons und Comtes, der hier anklingt (1920, 341, 347; vgl. Gross 2000, 155), widerstreitet deutlich Salomons Beteiligung an dezidiert jüdischen Projekten wie Martin Bubers Der Jude. Diese Beiträge sind daher noch zu betrachten. Es ist denkbar, dass Salomon hier, ähnlich wie Theodor Wiesengrund vier Jahre später (Wiggershaus 1988, 88), der gefühlsmäßig synthetisierten „complexio oppositorum“ (Schmitt 1923) des Katholizismus nahe stand. Das noch zu betrachtende Traktat gegen solche Versuchungen (Salomon 1922) wäre dann auch als biographische Aufarbeitung zu lesen. Doch zunächst zu seinen Beiträgen in Der Jude.

\section{Aufsätze in Martin Bubers Der Jude}

„Das Ethisch-Rationale ist beim Juden letzen Endes aus dem Mystischen gebürtig. “ Salomon 1920a, 251

Die von Martin Buber 1916-1924 herausgegebene Zeitschrift Der Jude war so etwas eine Sammlung für die ,jüdische Renaissance“ jener Zeit (Brenner 2001, siehe Lappin 2000). Es kamen zwar alle Stimmen aus dem deutschen Judentum zu Worte, aber ein Interesse an jüdischen Dingen muss gerade daher als Voraussetzung angenommen werden. Wo stand Salomon? Zwar ist die Tatsache, dass Salomon hier seit 1920 als Redakteur für den Bereich Soziologie tätig ist, vielsagend. ${ }^{39}$ Doch nicht leicht auszumachen ist, was er eigentlich zu sagen hat. Der Kontext ist die Debatte um den „Kulturwert“ des Judentums (Hackeschmitt 1997, 89 ff.). Ein Text von 1921 über Moses Hess (1812-75) sowie eine Rezension eines völkerpsychologischen Werkes von Elias Hurwitz geben sich ganz als Überblicksartikel. Im Medium der Nacherzählung werden allerdings eine dezidierte Assimilationskritik und eine Kritik am Marxschen Sozialismus gegeben; Alternativen werden dabei nicht ganz klar.

Die Kritik, die Salomon an der Assimilation der deutschen Judenheit äußert, greift wieder auf die Vernunftkritik seiner Dissertation (1916) sowie auf die Gegenüberstellung von Ost und West (1920) zurück: ganz ähnlich wie Freud begreift er das Judentum - dem er sich nicht explizit zurechnet, aber das darf man angesichts der Platzierung unterstellen primär als eine Gefühlsmacht, das mit Prädikaten wie „Leben“ (1920a, 250), „Seele“ (251) oder „Mystik“ (249) beschrieben wird. Das ist insofern etwas besonderes, als dem jüdischen Geist sonst oft ein seelenloser Rationalismus, eine „zersetzende Intellektualität“ zugeschrieben wurde

39 Martin Buber lädt Salomon am 28.2.1920 zur Mitarbeit ein (IISH, IIb/178). 
- durchaus nicht nur von Antisemiten, auch in Selbstbeschreibungen (die gleichwohl Spiegelungen gewesen sein mögen). ${ }^{40}$

Dem stellt sich Salomon hier entgegen, aber auf vermittelnde Weise. Der Topos der Rationalität, welche in damaligen Diskursen gern „den Juden“ als Charaktermerkmal zugeschrieben wurde - Salomon zitiert Werner Sombarts Ausspruch vom „abstrakt-verstandeshaften Wesen der Juden“ (Sombart 1911, 421; siehe 312-334) -, wird von Salomon relativiert, indem er die Beliebigkeit solcher Analogiebildungen auf die Schippe nimmt (Salomon 1920a, 249). Die Rationalität wird von ihm allerdings nicht irrationalistisch verdammt, denn „das emotionale Denken muss durch das Wissen hindurchgehen“ (250). Doch sie wird an ihren rechtmäßigen Ort verwiesen: „Ist der Intellekt denn Element oder nicht vielmehr ein Instrument der Seele?“ (249).

Salomon geht also einen Mittelweg: Die Zuschreibung typisch ,jüdischer“ Rationalitätsmuster, zumindest eines typischerweise hohen Grades von Rationalisierung, wie Salomon sie bei Theodor Mommsen, Werner Sombart, Renan und Hurwitz findet, wird nicht völlig zurückgewiesen. Doch wird ihr zum einen das mystische Element beigesellt (welches bei Salomon Prophetie wie Kabbala umfasst, 250); zum anderen wird die Rolle der Rationalität historisch relativiert - sie sei erst in der Diaspora in den Vordergrund getreten, und zwar rein defensiv: „Die ganze Intelligenz des Ghettos war nur auf die Abwehr bedacht“ (251).

40 „Eine der größten Gefahren unserer Tage ist der Intellektualismus, der besonders stark in der jüdischen Rasse ausgeprägt ist“" (so Eugen Diedrichs 1918, zitiert von Ingeborg Nordmann, in: Schoeps 1995, 256). Der Antisemit Houston Steward Chamberlain (1899) meinte, den Juden fehle das Mystische. „Wir können uns schwer einen jüdischen ,Mystiker“ vorstellen“ (Sombart 1911, 316). „Judentum im weitesten Sinne ist jene Richtung in der Wissenschaft, welcher diese vor allem Mittel zum Zweck ist, alles Transcendente auszuschließen“ (Weininger 1903, 428). Max Weber wollte aus der jüdischen Religion einen „,charakteristischen dialektischen Rationalismus“ ableiten (1922, 720; vgl. Liebeschütz 1967, 328 ff.; Rehberg 1989; Radkau 2005, 673-698). Freud räsonierte über den jüdischen „Fortschritt in der Geistigkeit“ (1937; siehe Vollmann in diesem Band); auch Walther Rathenau bediente dieses Klischee: Der liebe Gott „hat sich den Luxus gestattet, eine Portion reinen Geistes [...] in einen Topf zu tun, zu versiegeln und zwei Jahrtausende sozusagen in der Tiefe des Meeres zu versenken“. Heute seien sie das Salz der Erde, aber „für sich allein unproduktiv“, wofür Simmel ein Beispiel sei: „Eigentlich betreibt er nur ein Wechselgeschäft mit Gedanken“ (Rathenau 1977, 650). Unter Hitler eskalierten solche Stereotypen: „Was der Jude uns von der herrlichen schöpferischen Aufbauarbeit der idealistischen Systemdenker übrig gelassen hat, ist ein Wust von so genannten erkenntniskritischen Begriffsspaltereien, ein rein formalistischer Wissenschaftsbetrieb, der die Grundlagen unserer Weltanschauung entgöttert, entseelt“ (Schmidt 1938, 395; zum Antisemitismus vgl. Claussen 1987, Katz 1993b, Braun 2000, Ziege 2002, Benz 2004 und Holz 2005). 
Hier setzt nun seine radikale Assimilationskritik ein: Durch den Schutzschirm des Rationalismus habe das Judentum seine seelenhaften Eigenheiten lange bewahren können, wenn auch nur in Absonderung vom Rest der Gesellschaft. ${ }^{41}$ Mit der Aufgabe dieser Besonderungen durch die Assimilierung allerdings habe sich das Judentum selbst aufgegeben - eine „Emanzipation des Juden vom Judentum“ (1921a, 743; der Ausdruck erinnert an Karl Marx und Richard Wagner):

„Vor allem die Bildung hat den Auszug aus dem Judentum verschuldet. Die Exterritorialität und Exklusivität im Ghetto hatten das Judentum vor der äußeren Knechtschaft bewahrt. Der Auszug aus diesem Exil wurde zur völligen Diaspora, zur inneren Knechtschaft“ (Salomon 1921a, 43f.).

Mit dieser modernen Entfremdung erklärt Salomon auch die zuweilen anzutreffende Wahlverwandtschaft zwischen assimilierten Juden und dem Sozialismus („Im Kommunisten steckt der jüdische Paria“, 1921a, 745; zur Parallele bei Arendt siehe Schulz in diesem Band). Aus dieser instabilen Lage ergibt sich für Salomon nun eine doppelte Mission, einmal des Ostenjudentums für die ganze Judenheit, und sodann, zumindest zwischen den Zeilen, des Judentums für die Menschheit. Die Ostjuden nämlich hätten sich nicht vom „Rationalismus“ beherrschen lassen. ${ }^{42}$ Diese in die Moderne hinübergerettete Religiosität hat nun allerdings eine mehr als partikulare, nämlich eine welthistorische Aufgabe:

„Es ist [...] die messianisch-teleologische Richtung des jüdischen Geistes, die ihn über alle nationalen und sozialen Formen hinausdrängt. Der Irrationalismus der modernen Lebensmetaphysik und Gesellschaftsethik entstammt nicht einem abstrakten, weltfernen oder weltlosen Geist, sondern gerade einem Geiste, der in der Welt und im Menschen sich verwirklichen will“ (251).

Diese an Rudolf Euckens „Einheit des Geisteslebens“ (1888) und Bubers „Verwirklichung“ (1913) erinnernden Wendungen sind, wie schon in Westen und Osten, wörtlich gemeint: es geht Salomon um die Bildung

41 Salomon (1920a, 251; 1938) benutzt dafür das Bild aus Adalbert Stifters „Abdias“ (1847): Dieser ist nach außen ein erfolgreicher Kaufmann und starker Krieger; nach innen aber, in seinem Versteck in der Wüste [!], führt er ein inniges und traditionell jüdisches Familienleben. Dieses macht ihn stark für die diversen Schicksalsschläge, die er durchleben muss.

42 „Dagegen haben die Ostjuden, der Kern des Volkes, seit Chassidismus und Haskala eine innere Befreiung vollzogen und stehen diesem Rationalismus so gegenüber wie etwa die Ostasiaten, sie gaben ihr Wesen und Leben nicht den bloßen Mitteln preis, bei aller Technik und Wissenschaft bleibt der Vorrang in der Ordnung des Geistes der Religion gewahrt“ (Salomon 1920a, 250). 
einer welthistorischen Einheit („Noch ist die Einheit der Menschheit nicht in einer obersten Einheit des Geistes wiedergefunden“, 251), die mit der zionistischen Sammlung einsetzt. ${ }^{43}$ Zwar ist nicht klar, inwieweit Salomon paraphrasiert oder eigene Gedanken wiedergibt, doch die Tendenz ist deutlich: es geht wie schon bei Buber $(1911,26)$, Troeltsch und Karl Mannheim (1964, 92 ff., 606 ff.) um „Synthese“, um Vereinheitlichung angesichts der modernen Zersplitterungen und Verhärtungen. ${ }^{44}$

Salomon erblickt dafür ein großes kulturgeschichtliches Potential bei „den Juden, die als Volk nur eine Erlebnis- und Überlieferungsgemeinschaft bilden“ (1920a, 249). Es bleibt in diesen frühen Aufsätzen allerdings offen, wie die Vermittlung zwischen Universalismus und Partikularismus (Lappin 2000) genau zu denken ist, ist doch der Sprung vom Zionismus zur „Einheit der Menschheit“ recht abrupt. Martin Buber hatte zuvor bereits ähnlich argumentiert (1916, 65 ff.): die zionistischen Experimente hatten schon bei ihm eine „menschheitliche“ Bedeutung. Salomon formuliert hier sehr rezeptiv, ohne seine Quellen genau anzugeben, und ist damit nur aus dem Kontext ganz zu verstehen. Motivgeschichtlich lässt sich daran immerhin ablesen, dass Salomons Orientierung auf Überbrückung von Borniertheiten auf ein kulturell jüdisches Selbstverständnis zurückgeht. Denn er sieht diese Orientierung als einen jüdischen Erbteil an: „seine Mission [die ,des Juden“, CH] galt der Herstellung einer Einheit und Gemeinschaft in Gott, der in der Neuzeit die Vernunft heißt“" (1920a, 250).

Die moderne Borniertheit bemängelt Salomon hier am Marxismus: dieser ging gegenüber Moses Hess, der den Sozialismus ethisch begründete (was damals angesichts des mangelnden Proletariats gar nicht anders möglich gewesen sei), als „Kirche“ vor, warf ihn als „Ketzer“ aus dem „Tempel“ und belegte ihn in einer Art „Inquisition“ mit dem „Kirchenbann“ (1921a, 742f.). Karl Marx ging mit vielen seiner ehemaligen Mitstreiter in der Tat nicht eben sanft um. Das Besondere an Moses Hess insbesondere für jüdische Intellektuelle war aber, dass er - anders als etwa Bruno Bauer, der sich zum Reaktionär entwickelte (Brumlik 2000, 310f.) - seine frühen ethischen und sozialistischen Ideale beibehielt, diese aber in den Zionismus transformierte, zu dessen Gründungsfiguren er damit zählt. ${ }^{45}$ Damit hat Salomon die Linie eingeschlagen, die auch Franz Oppenheimer damals vertreten hat (siehe dazu Aron 1950).

43 „Mit dieser einzigartigen Rückbewegung wird die Geschichte, die seit der Zerstörung des Tempels für den Juden Zerstreuung unter die Völker ist, schließen und [...] die Einheitsbildung der Menschheit beginnen“ (Salomon 1921a, 746).

44 Zur „Synthese“ Ringer 1969, 344-357; Münch 1986, 748-755; cf. Barboza. 45 Zu Moses Hess vgl. Berlin 1980, 321-367; Liebeschütz 1970, 215-237. 


\section{Herausgabe französischer Frühsozialisten}

Ernst Simon, lange Zeit Lehrer an Franz Rosenzweigs Jüdischem Lehrhaus in Frankfurt, greift den hier anklingenden Topos der jüdischen Distanz zum Marxismus in einer anderen Situation erneut auf: 1934 schreibt er in einer Geburtstagsgabe für Franz Oppenheimer, in der auch Gottfried Salomon vertreten ist, es sei

„gerade heute, wo das Schlagwort vom ,jüdischen Marxismus‘ so weite Verbreitung [...] gefunden hat, die Feststellung bemerkenswert, dass der wohl gewichtigste wissenschaftliche Widerspruch gegen einen entscheidenden Punkt des marxistischen Systems von einem jüdischen Nationalökonomen erhoben worden ist“ (Simon 1934, Hvg. im Original).

Nach dem Ersten Weltkrieg arbeitet auch Salomon daran, eine Distanz zum autoritären Marxismus zu schaffen, ohne auf die ethischen und politischen Vorzüge des Sozialismus verzichten zu müssen. Zumindest ist das ein nahe liegendes Motiv dafür, dass Salomon in der Folge Frühsozialisten wie Saint Simon (1919, 1962) und Proudhon (1920) sowie Vorgänger von Marx wie Lorenz von Stein (1921) herausgibt oder sogar übersetzt. Dabei kam ihm sein französischer Erbteil sicher zugute, denn auch später arbeite er viel zu Frankreich (Belitz 1997, 288 ff., 404 ff.). Möglicherweise war mit dem Frankreichfokus der Versuch verbunden, sich als Frankreichspezialist zu etablieren, nachdem er die Oppenheimernachfolge nicht erhalten hatte. ${ }^{46}$

Dass diese Herausgaben als Gegengift gegen totalitäre Versuchungen verstanden werden können, heißt jedoch nicht, dass Salomon sich kritiklos an diese Autoren anhängt (das wäre angesichts der Bandbreite der von ihm herausgegebenen Autoren kaum denkbar, sind darunter doch auch extrem konservative wie Gumplowicz oder René Worms). So ist er in der Einleitung zu einer frühen Ausgabe gegenüber Saint-Simons Phantasma der klassenlosen Industriegesellschaft, das noch auf Daniel Bell und Helmut Schelsky stark eingewirkt hat, recht skeptisch. ${ }^{47}$

46 In der Rektoratsakte des Universitätsarchivs (UAF) wurde bei ihm als Fach neben „Soziologie“ die „Französische Staats- und Gesellschaftskunde“ nachgetragen (UAF Abt. 4, Nr. 123, Bl. 13r). Er gab 1930-1933 die Deutsch-Französische Rundschau heraus. Noch aus dem Exil schrieb er in Horkheimers Autorität und Familie über die französische Familie (1936).

47 „Die industrielle Gesellschaft ist nicht klassenlos, denn die Tendenz der Trennung des Eigentums und der Arbeit entwickelt scharfe Klassengegensätze“ (Salomon 1919, 26). Saint-Simons Programm sei eine „Wiedergutmachung der Revolution“ $(1919,18)$. 
Mit den Herausgaben der Frühsozialisten, die zum Teil noch heute zitiert werden, hat Salomon sich einen ersten Namen machen, allerdings noch kein rechtes Profil gewinnen können. Erstaunen lässt allerdings, dass er für den Antisemitismus vieler Frühsozialisten (Brumlik 2000, 282f.) so wenig Worte fand - im Gegensatz zu seinem Namensvetter Albert Salomon (1955), der die Frühsozialisten sogar als Ahnväter des Totalitarismus deutete. Überhaupt findet man in den nächsten Jahren bis auf Lexikonartikel keine gedruckten Äußerungen zu jüdischen Fragen mehr, das Thema ist regelrecht eingekapselt. Erst 1932, am Vorabend der Katastrophe, und verstärkt 1938 in der Pariser Emigration äußerst sich Salomon wieder dazu; dann allerdings sehr entschieden. Vielleicht hat das mit seinem Versuch der Etablierung als Fachsoziologe zu tun, von dem man eine weltanschauliche Zurückhaltung erwartete. Eine Rolle für das Schweigen in der Zwischenzeit könnte aber auch gespielt haben, dass er sich im Laufe seiner soziologischen „Desillusionierung“ zunächst von den religiösen Anfängen lösen musste. ${ }^{48}$ Kommen wir daher zu dem Buch, das dieses Thema behandelt.

\section{Habilitation bei Franz Oppenheimer in Frankfurt}

Gottfried Salomon hätte nach dem Weltkrieg in Berlin als freier Autor bleiben oder in einer Bank arbeiten können. ${ }^{49}$ Er entschied sich stattdessen für die Wissenschaft. 1921 wird er Franz Oppenheimers Assistent in Franfurt (als solcher arbeitete zeitweilig auch der marxistische Imperialismustheoretiker Fritz Sternberg, vgl. Papcke 1993, 50; Grebing 2005, 15) und habilitiert dort noch im selben Jahr. ${ }^{50}$ Salomon hat Oppenheimer während eines Urlaubs auf Föhr aufgesucht und rechnete auf seine Meriten als Simmelschüler. Man beschloss, dass Salomon als Assistent Oppenheimers an dem eigens für jenen gestifteten Lehrstuhl in Frankfurt

48 „Desillusionierung“ ist ein Wort, das Salomon oft und zustimmend benutzt (1926, 393, 419; in Bousquet 1926, 8; 1930, 62; 1931, 157 etc.). Es wird bereits von Carl Schmitt verwendet (1919, Inhaltsverzeichnis, unter II.2).

49 Nach Auskunft von Frank Benseler.

50 Oppenheimer bestätigt Salomon am 2.3.1921, dass er als Assistent eingestellt werde und seine Habilitation angenommen sei (IISH, IIb/866). In Vorlesungsverzeichnissen taucht Salomon seit dem Wintersemester 1921/22 auf: er liest über „Grundlagen und Geschichte der Soziologie“ und „Russische Revolutionäre des 19. Jahrhunderts“, hält eine Übung über „Soziallehren der Religionen: M. Weber, E. Troeltsch“ und bestreitet mit Oppenheimer das „Soziologische Kolloquium“ (http://db02.ub.uni-frankfurt.de/vorlesungsverzeichnis-se/pdf/1921wv.pdf, S. 46). 
(Wiggershaus 1988, 34) arbeiten und ihn während seiner häufigen Berlinaufenthalte vertreten sollte. ${ }^{51}$

Da sich keine Arbeit mit dem Titel findet, mit dem Salomon habilitiert wurde, ${ }^{52}$ nehme ich an, dass es sich bei dieser Arbeit um das zwei Jahre später publizierte Buch über das Mittelalter als Ideal der Romantik (1923) handelt - schon deswegen, als dies bis 1931 die einzige Buchpublikation Salomons bleibt. ${ }^{53}$ Sie behandelt eine zentrale Frage. Salomon musste früher oder später die Grundfrage beantworten: wenn eine übergreifende soziale „Einheit“ angestrebt war, wie ist diese möglich, ohne zugleich zu einer exklusiven und somit gewaltsamen zu werden? Seine Dissertation bei Simmel hatte gezeigt, dass das erlebnishafte Streben nach Einheit zu einem leeren Gehäuse werden kann, sobald es explizit gemacht wird; und seine späteren Einlassungen hatten den Marxismus als Negativbeispiel einer vereinheitlichenden „Kirche“ gebrandmarkt, die Andersdenkende gewaltsam ausschloss. ${ }^{54}$

Dass die sozialen Gegensätze gerade in jenen Jahren - zwischen Weltkrieg, Generalstreiks, Straßenkämpfen, Wirtschaftskrisen und beginnender „Nationalisierung der Massen“ - weit auseinanderklafften, machte die Frage umso dringender. Doch wie ist eine soziale Einheit, eine Überbrückung von Gegensätzen zu denken, soll sie mehr sein als eine bloß subjektive Einbildung derselben, die so schnell zur wohlmeinenden oder erzwungenen „Einhegung des Anderen“ wird? Diese Fragestellung teilte er mit dem ein Jahr jüngeren Karl Mannheim (18931947), dessen genialische Wissenssoziologie ganz im Zeichen einer solchen Verständigung zwischen den Weltanschauungen stand.

51 Berlin war für den Zionismus eine spannendere Stadt als das bürgerliche Frankfurt (Eloni 1987). An diese Episode knüpft sich eine Anekdote: Auf den Zweifel Salomons, ob es denn akzeptiert würde, wenn Oppenheimer häufig abwesend sei, habe sich Oppenheimer erhoben und ausgerufen, er sei der „Löwe Juda’s“ (mündlich nach Ottheim Rammstedt). Übrigens hatte auch Oppenheimer eine mystische Ader, wie ein veröffentlichtes Gedicht anzeigt („Ich bin der Wind, der Wald, die Sonne, / ich selbst der Quellstrom aller Kraft, / Und eine nie gefühlte Wonne / Sprengt meines Geistes Leibeshaft“ (in: Jüdische Rundschau, 28.3.1934, S. 17).

52 Obwohl die Habilitationsurkunde vom 15.1.1923 „Die Geschichte der neuzeitlichen Gesellschaft und Gesellschaftswissenschaft bis zur französischen Revolution“ als Thema angibt (IISH, IIb/1191; siehe Rüegg 1964, 625; Belitz 1997, 295), ist eine solche Arbeit nicht auffindbar.

53 Adorno schreibt an den Dekan: „er hat sich seinerzeit bei Franz Oppenheimer mit einer Arbeit über das Mittelalter als Ideal der Romantik habilitiert“ (13. Januar 1959; UAF, Fakultätsakte, Abt. 134, Nr. 490, Blatt 27).

54 Allerdings teilte der von ihm dagegengestellte Saint-Simonismus noch weit mehr Charakteristika der katholischen Kirche (siehe Salomon 1922, 121f.). 
Salomons erste Antworten auf diese Frage waren noch religiös gehalten. Vielleicht haben ihn die Besinnungen auf jüdische Themen (anders als der konvertierte Simmel bekannten sich seine Bezugspersonen Rathenau, Buber und Oppenheimer ja zum Judentum, wenn auch auf je verschiedene Weise) zu der Einsicht geführt, dass religiös majoritäre Lösungen das Problem nicht lösten, sondern eher verschärften. Jedenfalls ist seine Vorstellung von „Einheit“ in den 1920er Jahren, die seine fruchtbarste Schaffensperiode darstellen, geläuterter, sachlicher, indirekter und inklusiver als zuvor. In seinen synthetisierenden Herausgaben tritt er als Autor sogar mehr und mehr in den Hintergrund.

Wie in einem Scharnier entwickelt er in dieser programmatischen Läuterungsschrift eine Skepsis gegenüber vorschnellen Einheitskonkretisierungen. Salomon greift damit erneut ein Thema auf, das heiß diskutiert wurde. Er behandelt das Thema sogar relativ früh, auch wenn die späteren Kontrahenten auf seine Einlassung dazu nicht eingehen. Worum geht es? Eine prominente Antwort auf die Suche nach neuen politischen Einheitsformen waren damals neoständische Phantasien einer „gegliederten“ Gesellschaft, wie sie etwa Othmar Spann (1921) formuliert hatte, mit deutlichen Anklängen an das christliche Mittelalter sowie dessen politischen Adepten aus dem 19. Jahrhundert, Adam Müller, den Spann neu propagierte (Müller 1921, 1922; siehe jetzt Harada 2004).

Gerade unter konservativen Denkern dieser Zeit war dieses Denken jedoch keineswegs unumstritten. Im Nachgang ist diese Auseinandersetzung als „Adam Müller-Debatte“ bekannt geworden (Hoeges 1994, 98119, 168-177; Blomert 1999, 153). Beteiligt daran waren etwa Carl Schmitt, Friedrich Meinecke, Ernst Robert Curtius sowie in seiner Habilitation über Konservativismus von 1925 wieder einmal Karl Mannheim.

Organische Gesellschaftsvorstellungen in der zeitgenössischen Soziologie - neben Spann etwa bei Herbert Spencer oder Schäffle (1881) zu finden - hat Salomon später oft kritisiert (1925; in Worms 1926; 1949 etc.). Hier ist davon noch keine Rede, es geht eher um historische Prologemonena für eine solche Kritik. Um die Eigenart dieser Frühschrift von Salomon herauszuheben, bietet sich ein Vergleich mit der früheren Schrift von Carl Schmitt an. ${ }^{55}$

Carl Schmitt, ein Adept Max Webers, ging es in einer frühen Schrift (1919, $\left.{ }^{2} 1924\right)$ schon fast wissenssoziologisch darum, die „geistige Sig-

55 Auf diesen geht Salomon nur in einem Nachsatz ein: „Mag er [Adam Müller] auch kein lauterer Charakter gewesen sein, seine geistigen Fähigkeiten herabzusetzen, wie es sein neuester Ankläger, Carl Schmitt tut, geht nicht an“ (Salomon 1923, 120). Eineinhalb Jahrzehnte später wurde Carl Schmitt von Salomon erneut harsch kritisiert - zwischenzeitlich hat Salomon allerdings versucht, ihn für sein Soziologisches Jahrbuch einzubinden. 
natur eines Zeitalters“, der Romantik, zu erfassen. Darum geht es in Salomons Buch von 1922 ebenfalls. Auch untersuchen beide vor allem die angebotenen Einheitskonzeptionen. Der mittelalterliche Katholizismus kommt bei beiden nicht schlecht weg („Religiöses, politisches und ökonomisches Leben bildeten eine Einheit, da sie unter dem höheren Gesichtspunkt der Gemeinschaft zusammengefasst waren“, Salomon 1922, 109); wenngleich auch nicht er, sondern seine Thematisierung durch die Romantik das eigentliche Thema ist. Interessant an der Parallelisierung dieser beiden frankophilen Autoren (wobei Salomon auf frühsozialistische Autoren, Schmitt eher auf gegenrevolutionäre setzt) ist, dass beide die zentrale Figur Adam Müller zwar mit ähnlichen Vokabeln beschreiben, ihn aber radikal unterschiedlich bewerten. Worum geht es dabei?

Das Problem der Epoche aus Sicht der Romantiker war der Schwund der Einheit. Wie prominent dieses Denken noch damals war, kann man an Georg Lukacs' Theorie des Romans ablesen (der Roman als Form rettet eine Einheitskonzeption, wenn auch problematisch, über den Verlust der „Totalität“ hinüber). Schmitt kritisiert nun an Adam Müller, dass dieser das Problem zwar erkennt, neue Einheiten jedoch nur als subjektive und somit „occasionelle“ anbieten kann: „Was der mittelalterliche Mystiker in Gott gefunden hatte, suchte das romantische Subjekt selbst zu übernehmen“ (Schmitt 1919, 61/21924, 100).

Das ist Schmitts generelle Neuzeitkritik: das Subjekt und mit ihm die neuzeitliche politische Form, der Liberalismus, will zwar, kann aber keine wirkliche Einheit erzeugen. Durch diese „Wurzellosigkeit“ (1919, 47) verschreibt es sich daher den jeweiligen Augenblickskonstellationen.

Adam Müller als Prototyp politischer Romantik „kann alles verstehen und beliebig gutheißen, weil ihm alles zum Material seiner ästhetischen Gestaltung wird“ (1924, 114). Nur eine echte Einheit wie eben der Katholizismus könne das Subjekt erlösen, aber dazu hätten die Romantiker sich selbst aufgeben müssen: „Aber als sie [...] im Ernst fromme Katholiken sein wollten, mussten sie ihren Subjektivismus aufgeben“ (1919, 58/21924, 96). ${ }^{56}$ Eine solche totale Aufgabe des Subjektes an ein großes Ganzes (nur nicht an das falsche Ganze) haben Revolutionäre von Rechts wie Carl Schmitt damals gefordert; denn: „die echte Freiheit

56 Dass sich Schmitt selbst widerspricht, sei nur angemerkt: einerseits fordert er eine Aufgabe des Subjektes an Größeres, andererseits kritisiert er eben an Müller: „Er war jederzeit bereit, sich selbst aufzugeben“ $(21924,113)$. Wie noch später bei Schmitt ist deutlich, dass er starke Werturteile in seine Texte hineinschmuggelt: Selbstaufgabe an das eine ist gut, an das andere schlecht, weil er, Schmitt, eines höher bewertet als das andere, ohne dies allerdings noch auszuweisen. Er schwimmt auf einer antizipierten Zustimmungswelle seines konservativen Publikums und ist somit, wie schon Karl Löwith feststellte, selbst der Occasionalist, den er an Müller kritisiert. 
aber ist die freiwillige Aufgabe der Freiheit“ (Gehlen 1980, 176). Das war auch der Grund, warum sie die Weimarer Republik ablehnten, da deren offene und integrative Form eine solche Aufgabe gar nicht erforderlich machte (Gay 1970). Eine Einheit, die Besonderheit inkorporierte und die Individuen ansonsten freistellte, konnten sie nicht denken. Genau diese Einheitskonzeption ist indes das Thema von Salomon.

Schmitt kritisiert also an Müller, dass er die Einheit immer nur im Subjekt herstellt. Dadurch komme es zur ironischen „Entwirklichung der Welt in eine phantastische Konstruktion“, und daher eigne der Romantik ein spezifischer „Rationalismus und Intellektualismus“ ( $\left.{ }^{2} 1924,109\right)$. Näher geht dies so zu, dass stets ein „höheres Drittes“ (127) die realen Gegensätze auflöse und damit eine Entscheidung unmöglich mache.

Prominent ist hier die Methode der „Vermittlung“, und sie vor allem lehnt Carl Schmitt ab. Inhaltlich nämlich kann er weder mit der religiösen Fixierung noch mit der Suche nach Übergegensätzlichem unzufrieden sein, hat er doch beides in späteren Werken ebenfalls vertreten: der Staat als Essenz des Politischen war für ihn zwar der „neutrale“ Erbe der Religionskriege (und somit nichts anderes als etwas höheres Drittes), wurde damit aber gerade wieder religiös aufgeladen (Schmitt 1922). ${ }^{57}$

Es ist darum nicht auszuschließen, dass Schmitt hier gar nicht den eingeschlagenen Weg Adam Müllers kritisiert, sondern eher seinen persönlichen Werturteilen über dessen Person und dem, was Schmitt in ihm sieht, freien Lauf lässt. ${ }^{58}$ Mit Gross (2000) ist davon auszugehen, dass Carl Schmitts tiefer Antisemitismus schon im Frühwerk anzutreffen ist. Es ist daher nicht verwunderlich, dass die Kategorien, mit denen Schmitt Müller treffen will („Rationalismus“, „Intellektualismus“, seine „weibliche Natur“ - vgl. v.Braun 1992 - und vor allem die „Vermittlung“) auch im zeitgenössischen Diskurs über ,jüdischen Geist“ prominent waren. ${ }^{59}$

57 Es lässt sich allerdings mit Recht argumentierten, dass Schmitts Drang zur „Entscheidung“ in der Tat keine Vermittlung zuließ. Stritten sich zwei Parteien, so wurde zunächst die eine Partei zum höheren Dritten (zum „Staat“) erklärt, um sich dann doch für sich selbst zu entscheiden und den „Feind“ „entschieden“ auszuschalten. Das ist Schmitts Totalitarismus, den er bei seinem Vorbild Thomas Hobbes schon ähnlich vorfand (Kriele 1994).

58 Impulsiv illustriert hat diese These Nicolas Sombart (1991, 31-57). „Adam Müllers amoralisches Verständnis für alles und sein Gegenteil, seine Sucht, überall zu vermitteln [...], seine unmännliche Passivität“ seien „aus seiner weiblichen, pflanzenhaften Natur zu erklären“ (Schmitt 1919, 112 f.).

59 Deutlich ist die Ablehnung des Liberalismus als eines „Fremden“, auf deren Zustimmung seitens der Leser Schmitt rechnet: „Es ist ein Occasionalismus, der von einer Realität zur anderen entweicht, und dem das ,höhere Dritte‘ [...] etwas Entferntes, Fremdes, Anderes enthält, bei der beständigen Abbiegung auf ein anderes Gebiet, zum Anderen und Fremden schlechthin und schließlich, wenn die überlieferte Gottesvorstellung fällt 
Was ist demgegenüber der Fluchtpunkt von Salomons Buch? Zunächst ist deutlich, dass er - darin Mannheims Neubewertung vorwegnehmend - weit mehr Verständnis für die Lage Adam Müllers hat, indem er dessen „Standpunkt“ mitreflektiert (96, 113 - ein Vorgriff auf Mannheims „Denkstandort“). Ähnlich wie Tönnies, Durkheim und viele vor ihnen sah Müller die Gegenwart als Zwischenstadium zwischen der alten „Gemeinschaft“ des Mittelalters und der neu zu schaffenden Gemeinschaft der Zukunft (97). Der romantische Antikapitalismus Müllers (der nach Löwy 1997, 41 f. noch für die „jüdische Intelligenz“ der Jahrhundertwende typisch war) war insofern verständlich, als für die Kritiker der bürgerlichen Gesellschaft die Koalition mit dem Adel nahe lag. Die Gegenwart mit ihrem „Rationalismus“ bewertete auch Salomon ganz und gar nicht positiv: „es ist der individualistische Rationalismus, der die organische Gemeinschaft atomisiert und mechanisiert", paraphrasiert Salomon (100). Die Methode der Einheitserkenntnis, die Lehre vom Gegensatz (Müller 1804), die Schmitt so verabscheut, nennt Salomon eine „geniale Jugendschrift“ (99), und er gewinnt auch dem höheren Dritten einen Sinn ab (103). Auch darin ist ihm Mannheim dann gefolgt. ${ }^{60}$

Schließt sich Salomon damit den ständischen Mittelalterphantasien an? Gewisse Sympathien lassen sich in der Tat ausmachen (vgl. Löwy 1997). Doch diese sind nicht im Sinne einer simplen Bejahung reaktionäre Dystopien zu verstehen. Im Sinne einer Vermittlung geht es Salomon vielmehr darum, die gemeinsame Plattform zu formulieren, von der aus Romantik, Marxismus (110-114) und der soziologische Positivismus (121-123) die mechanizistisch verkürzten Züge der Gegenwart kritisieren. Er entwirft damit nicht nur eine Archäologie der Soziologie (vgl. Spaemann 1959), vielmehr gelingt ihm - obzwar erneut nur in Ansätzen, die nicht ganz transparent werden - ein Umwertung der konservativen Vergangenheit im Interesse emanzipatorischer Ansätze. War dies später bei Mannheim (1925, 89, 185), der meisterhafter formulierte, die Inan-

[!], das Andere und Fremde mit dem Wahren und Höheren eins wird“ (Schmitt 21924, 131). Nach Gross (2000, 34) war Schmitt Opportunist genug, um seinen Antisemitismus vor 1933 nicht offen, sondern nur „durch Andeutungen und versteckte Hinweise deutlich zu machen“. Dafür ist diese Stelle ein Beleg.

60 Mannheim bewertet insbesondere die „Vermittlung“ sehr hoch. In einer Spitze gegen Carl Schmitt setzt er sie mit „Entscheidung“ gleich („Das Erfassen des Einzelfalles ist Entscheidung, Vermittlung für das dynamische Denken“, so Mannheim 1925, 177). Mannheim zielt also - ähnlich wie, aber prägnanter als Salomon - auf eine „Rettung“ des konservativen Denkens für eine progressive Kritik der bürgerlichen Gesellschaft ab. Es geht um die historisch-dynamische Relativierung bürgerlich-rationalen Denkens, ohne dem Rückfall in reaktionäre Denkmuster zu erliegen, wie er bei Othmar Spann, Carl Schmitt etc. vorlag. 
spruchnahme der historischen Tugenden des konservativen Denkens für den Marxismus, so ist es hier vor allem der Gemeinschaftsgedanke, der angeeignet und damit dem reaktionären Denken entwunden wird. ${ }^{61}$

Es finden sich hier noch weitere Leitthemen späterer Werke. Salomon, der wenig später den übergegensätzlichen und übernationalen Charakter der Soziologie betonte - wobei es zeitgleich Bestrebungen zu einer rein und exklusiv „deutschen“ Soziologie gab, an denen Salomon dann spätestens 1933 scheiterte -, hinterfragt schon hier die Rückprojektion des Mythos einer deutschnationalen Einheit. ${ }^{62}$ Er versucht durch eine breite historische Kenntnis vorschnelle Konstruktionen, wie sie in der Soziologie noch heute beliebt sind, zu verunmöglichen. Der Preis dafür ist allerdings oft eine mangelnde Greifbarkeit seiner eigenen Thesen, so auch hier. Sie lassen sich nur mit einiger Liebe freilegen. Kommen wir damit nun zu seiner Hauptwirksamkeit als Assistent und Herausgeber.

\section{Begegnung und Parallele: Walter Benjamin}

Salomon ging also 1921 als Assistent Franz Oppenheimers zurück in seine Heimatstadt Frankfurt. Er tritt in der Lehre häufiger auf als sein „Vorgesetzter“ Franz Oppenheimer. Er gibt viele Überblicksveranstaltungen, etwa zu Geschichte der Soziologie oder des Sozialismus, behandelt Weber, Marx, Sombart, Troeltsch, und natürlich die Franzosen, zumal er seit 1930 dafür einen eigenen Lehrauftrag hat (Fn. 46). Es gibt eine interessante Schilderung der Lehrtätigkeit Salomons, in der sich die Spannungen zur späteren „Frankfurter Schule“ schon andeuten:

61 Salomon will die „missverständliche[n] Gleichsetzung von Romantik und Restauration“ (70) auflösen. „Die Herrschaft des absoluten, abstrakten Gedankens führte [...] zur mechanistischen Bureaukratie“ (78; vgl. Albert Salomon 1955), was verständlich wird, da der Rationalismus nicht nur die Revolution, sondern zuvor bereits den Absolutismus induziert habe (70). Es geht wie schon in den Aufsätzen für Buber um eine „Vermittlung“ der Rationalität mit den anderen Mächten des Lebens wie etwa „Gemeinschaft" und „Geschichte“.

62 „Es ist sinnlos [,] bis ins 17., 18. Jahrhundert von einer Einheitlichkeit der Deutschen (als Staats- oder Kulturnation) zu reden. [...] Die nationaldeutsche Bewegung geht kulturell wie politisch von dem völkisch gemischten_Kolonistengebiet aus“ (16). „Die Romantik [...] erwächst auf religiösem Boden, [...] wird zum ästhetischen und politischen Nationalismus und endet im Katholizismus, der wie der Klassizismus übernational ist“ (15). Bei wichtigen Figuren wie Wackenroder und Novalis sei „der Nationalismus, wie überhaupt bei den Deutschen, mit einem Universalismus verbunden“ gewesen (44, vgl. 49). 
„Ein besonderes Vergnügen blieb aber das Kolloquium in ,Forells Garten“ in Bockenheim, das Gottfried Salomon einmal in der Woche über das gerade herausgekommene Buch von Troeltsch; Der Historismus und seine Probleme veranstaltete. Dabei ging es in Forells Garten in Bockenheim zwischen 8 und 12 Uhr abends sehr lebhaft zu. Theodor W. Adorno und Walter Benjamin brachten in jugendlichem Überschwall mit Geist und Witz Salomon immer wieder zu schwierigen Verteidigungsmanövern; von Troeltsch blieb dabei ohnehin kaum ein Faden übrig. Für die Zuhörer war dieses Schaugefecht ein wahres Fest. Die gute Meinung von Troeltsch, die ich in Berlin gewonnen hatte, wurde dabei nicht erschüttert“ (Hans Achinger, in: Schefold 2004, 125). ${ }^{63}$

Ein anderer Bericht von Norbert Elias, der ca. sieben Jahre später handelt, erzählt von Treffen Karl Mannheims mit Adolf Löwe und Paul Tillich, die im Keller des Institutes und dann im Cafe Laumer stattfanden:

„Es ist möglich, dass auch Professor Salomon dabei mitwirkte, aber daran kann ich mich nicht mehr genau erinnern. Dasselbe gilt von Professor Bergsträsser. Mein Gedächtnis verlässt mich hier“ (in: Schefold 2004, 97).

Man kann vielleicht schon hieran erahnen, dass Salomon es auch in Frankfurt nicht immer einfach hatte: er bewegte sich, anfangs neben Fritz Sternberg, ${ }^{64}$ als habilitierter Assistent im Schatten Oppenheimers, später im Schatten Mannheims, der ihm die Assistenzstelle erhielt, und war auch vom späteren „Institut für Sozialforschung“ nicht wirklich integriert. Wie gesehen kam er in der Lehre früh in Kontakt mit deren späteren Mitgliedern (mit Leo Löwenthal bereits 1918). Besonders anfangs war er daher für sie wichtig, da er einer der wenigen Soziologen war und als Assistent eine Brücke zu den Honorarien der Universität darstellte. Dabei haben diese „kritischen“ Theoretiker mit den Fachsoziologen

63 Das Geschilderte muss sich laut Vorlesungsverzeichnis im Sommersemester 1923 abgespielt haben. Ein Brief Benjamins an Salomon vom 1.12.1923 (Benjamin 1995 II, 383) legt nahe, dass er es nicht so arg getrieben haben kann, zumal sie gleichaltrig waren: „wogegen Ihre kurze Andeutung, dass das Semester noch tumultarischer sich anlasse als das vergangne mich für Sie denn doch besorgt macht. Weniger noch für die Arbeit [...] als für die Gesundheit“. Auch Adorno, der schon eher einmal provozierte, berichtet von diesem Abend (Gesammelte Schriften 20.1, 173).

64 Schivelbusch berichtet, wie dieser eine Vorlesung Oppenheimers in Franz Rosenzweigs „Jüdischem Lehrhaus“ übernimmt und verpatzt: „Ebenfalls nicht den erhofften Zustrom brachte eine Vorlesung, für die er [Rosenzweig, $\mathrm{CH}$ ] den Frankfurter Soziologen Franz Oppenheimer [...] und dessen Assistenten Fritz Stern[berg, $\mathrm{CH}$ ] gewonnen hatte. Die erste Vorlesung, von Oppenheimer gehalten, war gut besucht, alle darauffolgenden von Stern schwach“ $(1985,46)$. Man sieht hieran jedoch die Rolle, die Assistenten für Oppenheimer spielten. 
Frankfurts - Oppenheimer, Salomon, später Karl Mannheim und Norbert Elias sowie weiteren sozialwissenschaftlich Arbeitenden wie Martin Buber, Hugo Sinzheimer, Hendrik de Man und anderen - sonst nicht unbedingt den Kontakt gesucht (Wiggershaus 1988, 128f.). Salomon war jedoch früher da als sie, daher war an ihm kaum ein Vorbeikommen.

Im amerikanischen Exil hat sich diese Lage dann umgekehrt - Salomon hat davon allerdings kaum profitiert. Man erhält den Eindruck, dass sie sich respektiert, aber nicht unbedingt gemocht haben; das gilt vor allem für Adorno. Doch auch Horkheimer, mit dem er sich zu verstehen meinte, setzt sich nur selten für ihn ein, obwohl Salomon ihn in den verschiedensten Lebenslagen darum bittet. ${ }^{65}$ Die ironische Parallele ist nun, dass es Walter Benjamin, dem später so hochgeschätzten Theoretiker, zeitweilig nicht anders ging (Wiggershaus 1988, 217f.). Vielleicht ist es auf die Spannungen zwischen Salomon und Adorno zurückzuführen, dass die Rolle, die Salomon für Benjamin gespielt hat, in der ersten, von Adorno und Scholem besorgten Ausgabe von Benjamins Briefen nicht klar heraustritt. Man kann sie dort nur aus Schreiben an Dritte erahnen:

„Ich weiß nicht, ob ich dir schrieb, dass Dr. Salomon unter nicht ungünstigen Auspizien meine Dissertation und die Wahlverwandtschaftenarbeit Prof. Schultz übergeben hatte“ (Benjamin an Scholem, 1. Feb. 1923, in: Benjamin 1966, 297; ungekürzt in Benjamin 1995 II, 311 f.).

Was ist der Hintergrund dieses Schreibens? Salomon, der Benjamin schon gekannt haben muss, ${ }^{66}$ hat eine besondere „Vermittlertätigkeit“ vollbracht durch die Hilfestellung, die er Walter Benjamin für seine Habilitation - wenn auch vergeblich - gewährte. Er hatte ihm zum Zwecke seiner Habilitation über das barocke Trauerspiel den Kontakt zu Franz Schultz, Professor für deutsche Literaturgeschichte, ermöglicht, da - wie sich später tatsächlich herausstellte - Hans Cornelius, der Philosoph, diese nicht annehmen würde (Benjamin 1995 II, 345, Adorno hat er ebenfalls abblitzen lassen, Wiggershaus 1988, 98f.). Benjamin schreibt allein 1923 acht Briefe an Salomon (siehe dazu Kambas 1982). Aus diesem Briefwechsel geht hervor, dass sie sich ihre Schriften zusenden (Benjamin 1995 II, 294), ihre Familien gegenseitig besuchen, sich über

65 Der Briefwechsel zwischen Ihnen im Nachlass Horkheimers im Archiv der Universitätsbibliothek Frankfurt belegt das. „Haben Sie jetzt ein Interesse an einem Artikel zur Soziologie des Anti-Semitismus?“ fragt Salomon am 16.10. 1938 aus Paris (Nachlass I 22, Nr. 42) - dieser oder ähnliche Texte sind bis auf eine Ausnahme nie über Horkheimer erschienen.

66 Salomon 1922 zitiert Benjamins Dissertation (1921). Beide Bücher wurden übrigens gemeinsam rezensiert (Sparnaay 1924). 
akademische und politische Projekte ${ }^{67}$ sowie ihre (oft angeschlagene) Gesundheit austauschen und Salomon sich immer wieder für Benjamin einsetzt, sogar bei der Wohnungssuche $(331,518)$.

Dafür beteiligt sich Benjamin dann an einer - nicht zustanden gekommenen - Geburtstagsgabe für Salomon (360, an Buber, 24.10.1923; 518). Deutlich ist auch, dass die beiden sich für Ihre Publikationen ins Vertrauen ziehen $(384,400)$. Salomon erwägt sogar, Benjamin ins „Jahrbuch“ (für Soziologie, 491; 1995 III, 32) aufzunehmen. Aus Benjamins Habilitation, an der er über Jahre saß (oft entschuldigt er sich bei Salomon brieflich, dass er noch immer nicht fertig sei), ist schließlich nichts geworden, sie fiel in Frankfurt gnadenlos durch. Auch dies aber erfuhr er über Gottfried Salomon, wie er Scholem schreibt. ${ }^{68}$

Freilich äußerst sich Benjamin gegenüber Dritten reserviert über Salomon. ${ }^{69}$ Diese innere Distanz mag auch dafür verantwortlich sein, dass sie nach 1933 in Paris nicht nennenswert kooperierten, obwohl beide dort Jahre im Exil verbrachten. Beide waren stark in ihre Projekte vertieft - Benjamin saß am Passagenprojekt, Salomon u.a. an einer französischen Dissertation. Salomon trauert schließlich mit dem gemeinsamen Freund Fritz Lieb über das tragische Ende Benjamins. ${ }^{70}$

67 „Hoffentlich hat die Gefahr, die jetzt über Deutschland hereinbricht, zur Folge, dass Sie in etwas aus Ihrer politischen Reserve heraustreten und sich dem Plane einer Organisation der Intellektuellen zuwenden, der mir, als sie ihn bei meinem letzten Besuche entwickelten, so großen Eindruck machte“ (Benjamin an Salomon, 18.1.1923, Benjamin 1995 II, 303). Dieser Plan weist schon ein wenig auf spätere Aktivitäten in Davos und Paris voraus.

68 „Alsbald wandte ich mich an Salomon um genauere Auskunft. Dieser konnte auch nichts ermitteln, als dass allgemein man zur schleunigsten Rücknahme des Gesuches riete, um die offizielle Zurückweisung mir zu ersparen“ (Benjamin an Scholem am 21.7.1925; in: Benjamin 1966, 392/1995 III, 59).

69 „Im übrigen legt er sich für mich außerordentlich ins Zeug und es trägt zu den Schwierigkeiten des Lebens in der Stadt [...] bei, dass ich seine Aktion mit freiem Gefühl nicht aufnehmen kann. So dankbar ich gestimmt bin, es ist in ihm zuviel, dem ich mich verweigere. Und dabei hat er Zuspruch aus mehr als einem Grunde nötig, denn äußere Erfolge sind jetzt seine einzigen. (Er ist zum Professor vorgeschlagen.) Ein Hauptmotiv seiner Betriebsamkeit in meiner Sache ist denn auch [...] dass er mich hier braucht“ (Benjamin an Scholem, 19.2.1925, Benjamin 1995 III, 17). Dass Benjamin Salomon immer wieder zur Hilfe anhielt, verschweigt er hier gegenüber Scholem. Das Gegenstück zu den äußeren Erfolgen könnte möglicherweise die Trennung von seiner ersten Frau oder den Verlust des Ersparten durch die Inflation meinen.

70 „Mein lieber Lieb, der Tod unseres Freundes, dem ich früher öfter helfen konnte und der so einsam bitter wenige hatte, die seine preziöse Nuance einer Philosophie des Endes verstanden - ist mir sehr nahe gegangen. Diese Lösung liegt so nahe als eine Ausflucht aus der Falle, eine Antwort auf 


\section{Herausgeberschaften der 1920 er Jahre}

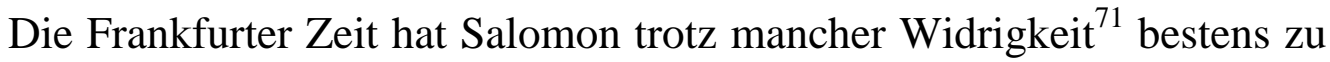
nutzen verstanden. Eine beflügelnde Rolle mag dabei die Aussicht auf eine Professur gespielt haben, für die die Publikationstätigkeit sicher nicht von Nachteil war. 1925 kam es sogar zu einer außerordentlichen Professur. Dabei blieb es jedoch. Gerichtlich wurde bei der späteren Wiedergutmachungsverhandlung dann festgelegt, dass Salomon, wären die Nationalsozialisten nicht an die Macht gekommen, 1936 (also mit 44 Jahren) eine reguläre Professur erlangt hätte. ${ }^{72}$ Darüber lässt sich natürlich nur spekulieren. Sicher ist jedenfalls, dass Salomon ungeheuer rege war. Allein die Liste seiner Briefpartner jener Jahre ist unfassbar. ${ }^{73}$

Allerdings haben die immensen Herausgeberschaften das Fehlen eines eigenen „Hauptwerkes“ in den Augen vieler Kollegen nicht aufgewogen. Doch Erich Preiser, der schon damals Professor in Frankfurt war, ist in seiner Einschätzung Recht zu geben, dass nicht nur die Anzahl der Herausgaben ungewöhnlich ist (zwischen 1919 und 1928 gibt Salomon 21 Bücher heraus, meist mit Einleitungen). Auch die dahinter

die unwürdige Behandlung, als Ermüdung des tranqué. In M[arseille] fühlte man sich so unsicher" (Salomon an Lieb, Karte vom 22.9.1940, nach Kambas 1983, 214 f.). Kambas erläutert das Verhältnis so: „Als Vertreter des freiheitlichen Bürgertums gehörten Lieb und Salomon dem LutetiaKreis und dann dem Komitee zur Bildung einer Volksfront für Deutschland an; noch in der vielversprechenden Anfangsphase hat Benjamin Fritz Lieb kennengelernt. Gottfried Salomon wiederum kannte Benjamin seit seinem Habilitationsversuch in Frankfurt, wo ihm jener außerordentlich beigestanden hatte. Das Arbeitsvorhaben Benjamins über die Pariser Passagen dürfte beide unter den Exilbedingungen zusammengeführt haben“ (Kambas 1983, 204). Letzteres ist durchaus fraglich.

71 Dazu Notker Hammerstein: Salomon „habilitierte sich hier auf einem Zwischengebiet zwischen Soziologie und politischer Ideengeschichte. Nur ein Einspruch der Philosophischen Fakultät versperrte ihm einen Lehrauftrag für Geschichtsphilosophie. Ein solcher habe nicht bei den Wirtschaftswissenschaftlern, sondern bei den Philosophen zu resortieren. 1925 zum nichtbeamteten, außerordentlichen Professor ernannt, verlor er in der Inflation seine bescheidenen Mittel und hatte große Schwierigkeiten, durch Lehraufträge seine Existenz zu sichern“ (Hammerstein 1989, 133).

72 „Als Zeitpunkt, in dem der Geschädigte voraussichtlich ordentlicher Professor geworden wäre, wird der 1. Januar 1936 festgestellt" (Wiedergutmachungsbescheid vom 11. März 1958, UAF, Abt. 4, Nr. 123, Bl. 34).

73 Das Amsterdamer Archiv, dessen Bestände nur bis 1933 reichen, zählt allein 1268 Briefpartner (http://iisg.nl/archives/nl/files/s/10767974full.php). Darunter sind neben Größen des Faches aus dem In- und Ausland (Maurice Halbwachs, Marcel Mauss, Thorstein Veblen etc.) auch Jüngere wie Alfred Seidel, Alfred Sohn-Rethel, Leo Löwenthal oder Werner Cahnmann. 
stehende Konzeption ist beeindruckend. ${ }^{74}$ Da ist zum einen die schiere Bandbreite der Herausgaben und die Fülle der in den jeweiligen Einleitungen aufbereiteten Materialien. Salomon war keineswegs auf Frühsozialisten festgelegt, sondern verlegte auch konservative bis reaktionäre Denker wie René Worms, Vilfredo Pareto (Bousquet 1926), Georges Sorel oder Ludwig Gumplowicz. Und seine Einleitungen sind zuweilen eigenständige Traktate - die lange Einleitung zu Lorenz von Stein etwa (1921) gibt eine Geschichte des soziologischen Denkens im Deutschland des 19. Jahrhundert, vor der eigentlichen „Erfindung“ der Soziologiegeschichte; die Einleitung zu Barnes (1927) hingegen übernimmt etwas ähnliches für die amerikanische Soziologie. Salomon ist zudem stets bemüht, in diesen Herausgaben ein Konzept erkennen zu lassen. Dieses ist am besten ausgesprochen in den Vorreden zu seinen Jahrbüchern für Soziologie (1925-1927 in vier Bänden), zumal eine Vielzahl der Herausgaben um diese herumgelagert sind: „diesen Jahrbüchern ist angegliedert eine ,Bibliothek der Soziologie und Sozialpolitik““ (Jahrbuch I, 3).

Die Jahrbücher waren gedacht als Plattform für eine Neuordnung der deutschen Soziologie nach dem Weltkrieg. Die Soziologie war aus dem Weltkrieg verändert hervorgegangen: viele ältere Mitglieder der Deutschen Gesellschaft für Soziologie (DGS) waren nicht mehr dabei, nur zum Teil weil sie, wie Max Weber und Simmel, verstorben waren. Es gab eine Reihe neuer Akteure, und auch die Themen hatten sich gewandelt: der erste Soziologentag der neu gegründeten DGS behandelte symptomatischerweise Das Wesen der Revolution (DGS 1922). Das bedeutete allerdings keineswegs eine Einigkeit hinsichtlich der Bewertungen derselben. Im Gegenteil, die Fronten brachen immer offener auf. ${ }^{75}$

Dabei ist zu bedenken, dass zeitgleich eine fortschreitende Militarisierung politischer Konflikte um sich griff, die allmählich auch in die

74 In einem Gutachten im Rahmen der Wiedergutmachungsverhandlungen schreibt Erich Preiser dazu: „Es ist gewiss zuzugeben, dass bei Berufungen im allgemeinen mehr auf größere eigene Arbeiten gesehen wird als auf Veröffentlichungen der Art, wie sie Salomon publiziert hat. Auf der anderen Seite aber stehen die hohe Qualität eben dieser Veröffentlichungen und die ungeheure Anregung, die Salomon dem Leser wie dem Hörer gibt“ (21.6.1957, UAF, Akte BZ: 256, LZ: 1928-79). Weitere hochinteressante Gutachten kamen von Leopold von Wiese, Arnold Bergsträsser und G. Weippert. Horkheimer hingegen weigerte sich auf Anfrage, darüber zu gutachten, da er über Salomons akademische Laufbahn - kaum glaubhaft keine Angaben machen könne.

75 Max Adlers Ausführung beispielsweise wurde abgeschnitten (DGS 1923, 44). Besonders tumultarisch verlief der Züricher Soziologentag von 1928, wo es zur offenen Auseinandersetzung zwischen Alfred Weber und Karl Mannheim kam. Gottfried Salomon nahm aktiv nur 1926 in Wien teil (DGS 1927, 102-109, 173-176; cf. Kaesler 1984, 603; vgl. Kaesler 1981). 
Universität hineinreichte (Elias 1990, 57, 128). Salomon versuchte nun, eine theoretische Plattform für diese neue Soziologie in all ihren Gegensätzen zur Verfügung zu stellen, ohne dabei inhaltlich Vorgaben zu machen. Allein aus dem deutschsprachigen Raum gewann Salomon für eine Mitarbeit u.a. Max Adler, Karl Mannheim, Robert Michels, Franz Oppenheimer, Ferdinand Tönnies, Alfred Vierkandt und Leopold von Wiese; eine mehr als repräsentative Auswahl. Mit anderen wie Carl Schmitt, Georg Lukacs oder Alfred Weber stand er lange in Verhandlung. Dazu kamen aus der internationalen Soziologie Autoren wie Charles Ellwood, Maurice Halbwachs, Gaetano Mosca oder Piritim Sorokin. Doch was war nun, jenseits der bloßen Sammlung, Salomons Konzept dabei?

„Es handelt sich mir darum, die Isolierung der deutschen Wissenschaft aufheben zu helfen, internationale Zusammenarbeit wieder zu ermöglichen. [... D]ie politischen Bindungen und Beeinflussungen sollten durch Auseinandersetzung der aktuellen und historischen Probleme bewusst und verglichen werden [...] Der übernationale Gedanke einer geistigen Einheit, welche Europa und Amerika umfasst, tritt in der wissenschaftlichen Arbeit wieder hervor“" (I, 1).

Es lassen sich klar drei Absichten erkennen: zum einen geht es darum, der einseitig „deutschen“ Soziologie entgegenzutreten, wie sie sich in Abschottung vom „Westen“ besonders zum Ersten Weltkrieg hin ausgebildet hatte - man denke an die Kriegsschriften von Werner Sombart, Max Scheler und Ernst Troeltsch sowie an das, was sich bei Carl Schmitt, Hans Freyer oder Hans Stoltenberg bereits wieder abzuzeichnen begann. Das geschieht durch die internationale Öffnung und die „Vermittlung“ anderssprachiger Soziologietraditionen. ${ }^{76}$ So ist Salomon auch in einer anderen Reihe, den Soziologischen Lesestücken, um ein distanziertes Verständnis der deutschen Tradition bemüht. ${ }^{77}$

76 Man vergleiche das musikalische Bild Salomons („Die geistige Zusammenarbeit gleicht einem Konzert, instrumentiert von den Stimmen der Völker, das durch Proben [...] gefördert wird“; Jahrbuch I, 1) mit dem der Völkischen: hier erscheint der Nationalsozialismus als „Grundton“, der nötig sein, damit sich die vielfältigen „Obertöne“ nicht mehr gegenseitig „vernichten“ (Schwarz 1934, 519). Hier wird Adornos Lesart des Musikgeschmacks plausibel.

77 Salomon setzt eine deutsche „Sozialphilosophie“ von der Soziologie ab: „Aus den politischen Schicksalen Deutschlands im letzten Jahrhundert ergibt sich die bloß philosophisch-deduktive Erklärung; nur aus dem politischen Schicksal des deutschen Bürgertums lässt sich verstehen, warum die Versuche einer deutschen Gesellschaftslehre zu einem apokryphen Schrifttum geworden sind“ (Lesestücke II, 2; vgl. Henning 2005, 251 ff.). 
Zweitens will sich Salomon damit als Fachvertreter profilieren. ${ }^{78}$ Schließlich geht es innerhalb der eigenen Tradition darum, weltanschauliche und politische Gegensätze der Zeit durch einen theoretischen Dialog auf einer neutralen Plattform im Sinne Schelers (1927) „auszugleichen“. Salomon hatte lange nach einer solch „höheren Einheit“ gesucht. Nun hat er sie und nutzt sie ausgiebig: es ist die Soziologie!

„Gerade das aktuellste Gebiet, die Soziologie, scheint geeignet, die Entgegensetzungen [!] und Zusammenhänge der Sozialwissenschaften in den verschiedenen Ländern darzustellen. Hier treffen sich Rechts-, Staats-, Geschichts- und Geisteswissenschaften. Hier ist ein neuer Standort [!] gegeben, indem der unsicher gewordene Boden heutigen politischen und kulturellen Lebens in seiner Problematik bekannt und erklärt wird“ (Jahrbuch I, 1).

Soziologie wird als eine doppelt offene Disziplin entworfen: sie behandelt zwar die „Tatsachen“ (Jahrbuch II, iv) der „sozialen Prozesse[n] und Institutionen“ (Jahrbuch I, 2) und ist somit empirisch und neutral (3). Doch gerade durch ihre Nichtfestgelegtheit, ihre Offenheit gegenüber Nachbarfächern, wird sie zur universalen Gesamtwissenschaft des Sozialen, ohne dass eine Schule den anderen etwas vorschreiben könnte. Damit gehört Pluralismus konstitutiv zur Soziologie, und eine reflexive Selbsterkenntnis dessen ebenso („Gesamtwissenschaften werden durch einen Standpunkt bestimmt“; I, 2). Sie kann sich indes nicht auf ihre Neutralität, die sie gleichwohl braucht („Meine Stellung als Herausgeber [...] musste möglichst neutral sein“; I, 1), zurückziehen. Vielmehr muss sie ihre Position als ausgleichende Plattform erkennen und offensiv nach außen hin vertreten - das ähnelt Hannah Arendts „reflexivem“ Paria:

„Da die Soziologie aber Ausdruck einer neuen Geisteslage [...] ist, so hat die Auseinandersetzung mit anderen Wissenschaften und der Streit um die Methoden einen weltanschaulichen Sinn“ (Jahrbuch I, 1; cf. Barboza 2005, 218).

78 Salomon erklärt Leopold von Wiese brieflich (14.1.1927): „Wir sind an einem Stadium der Soziologie angelangt, in dem wir als Herausgeber überhaupt erst gewisse einheitliche Richtungen herausbilden müssen und durch das Nebeneinander langsam ein Miteinander bilden können. [...] Ich lege nur den größten Wert darauf, dass sie die Planmäßigkeit meiner Bestrebungen anerkennen, das Fach zu organisieren und studierbar zu machen. Die Herausgabe apokryph gewordener Klassiker (Stein und Gumplowicz), ausgewählter Lesetücke, einer großen Übersetzungsbibliothek, in der zunächst vorzugsweise Amerikaner erscheinen (zunächst Ellwood und Veblen), die Vorbereitung einer großen Durkheimausgabe dienen nur diesem Zweck“ (IISH, IIb/1271). 
Salomons Herausgaben sind darum keineswegs einfach als weltanschauliches Bekenntnis zum Herausgegebenen zu lesen. Im Gegenteil, seine Einleitungen weisen meist scharf auf Probleme und Schwachpunkte des jeweiligen Buches hin. ${ }^{79}$ Es geht um Verständnis der Gegensätze. Nur so ist die ungeheuer breite Palette der Herausgaben zu verstehen.

Salomons Konzept ist damit erstaunlich aktuell: Eine Soziologie, die das Gespräch wagt, die sich nicht in Schulen und Nationalstilen verschließt, ist auch noch heute ein Desiderat. Das Konzept von Einheit, das Salomon nun unterstellt, ist gegenüber den Frühschriften gereift: er arbeitet zwar auf Vereinheitlichung hin, aber ist skeptisch gegenüber voreiligen Einheitsbehauptungen, vor allem, wenn sie aus einer Feder stammen. ${ }^{80}$ Ein Verständnis kann sich nur im gemeinsamen Widerstreit ergeben. Das ist wahrscheinlich auch der Grund dafür, warum sich Salomon als Autor immer mehr zurücknimmt und eher als Initiator dieses Gespräches auftritt - ob als Herausgeber oder dann als Organisator.

\section{Begegnung und Parallele: Karl Mannheim}

Interessant an dieser Positionierung ist, dass diese neutrale und auf Ausgleich bedachte Position sich nicht einfach als „liberal“ versteht, wie man heute vielleicht annehmen könnte. Aus Sicht der Kommunitaristen ist die liberale „Einheit“ zu abstrakt und kalt, um auf bestehende Gegensätze überhaupt eingehen zu können, die sie schlicht übergehe. Einen ähnlichen Ansatz verfolgte bereits Salomon, indem er bei der Freilegung der Geschichte soziologischen Ausgleichsdenkens eher konservative Denker in den Vordergrund rückt, die die historischen Besonderheiten

79 Hinsichtlich Paretos etwa, der mit den italienischen Faschisten soeben auch in der Politik prominent geworden war, schreibt Salomon: „ich sehe in Paretos Soziologie eine Fortsetzung des sozialmechanischen Systems von Winiarsky und halte den Zusammenhang mit der mathematischen Ökonomik für entscheidend, denn wie in der Ökonomik, so tritt in seiner Soziologie der Mechanizismus hervor“ (in: Bousquet 1926, 7). „Eine soziale Mechanik aber ist der sozialen Realität nicht entsprechend und lässt keine Anwendung, als Politik, zu“ (5). Diese Position ist besonders hinsichtlich der heute hegemonialen neoliberalen Lehre interessant, die sich ebenfalls oft hinter mathematischen Modellen verschanzt. An Pareto zeigt Salomon beispielhaft die antisozialistische und autoritäre „Tendenz“ einer „ultraliberalen“ Wirtschaftspolitik auf (7).

80 „Wie auf einem Kongress stehen [...] die Äußerungen nebeneinander, denn nur ein einziger Vertreter oder eine Schule könnten einen systematischen Zusammenhang bieten. Ich möchte vielmehr einen Überblick und ein von verschiedenen Seiten behandeltes Thema für geeignet halten, den Stand und die Probleme zusammengehörig darzustellen“ (Jahrbuch III, 3; II, iii). 
analysieren (etwa Adam Müller, Lorenz von Stein oder die Frühsozialisten - „Liberale“ wie Pareto werden dagegen harsch kritisiert). ${ }^{81}$

Dies wie vieles andere erinnert stark an Karl Mannheim. ${ }^{82}$ Allerdings hat Salomon viele dieser Gedanken oft schon vor Mannheim entwickelt, wenn auch längst nicht so prägnant. Worauf sind diese erstaunlichen Parallelen, die bis in die Wortwahl gehen („Standort“), zurückzuführen? Es ist wenig wahrscheinlich, dass einer den anderen kopiert hat. Anzunehmen ist eher, dass die beiden eine Zeitlang ihre Gedanken ausgetauscht haben und darauf wie auf eigenes zurückgriffen. Salomon gibt 1925 einen Aufsatz Mannheims heraus (Jahrbuch I). Dabei kommt es zu einem Briefwechsel. Daraus geht hervor, dass Salomon Mannheim seit 1924 zu seiner Habilitation beraten und diese sogar Korrektur gelesen hat. ${ }^{83}$

Als Karl Mannheim allerdings 1929 die Oppenheimer-Nachfolge antrat, auf die auch Salomon spekuliert hatte, ${ }^{84}$ übernahm er zwar Salomon

81 „Als Soziologie unterscheidet sie [St.-Simons Theorie, $\mathrm{CH}$ ] sich prinzipiell von der klassischen und liberalen Ökonomie, an die Stelle der Untersuchung abstrakter Wirtschaftsfaktoren [...] tritt die Betrachtung konkreter Wirtschaftsgruppen. Indem die Soziologie den Gedanken der Entwicklung auf die Wirtschaft anwendet, setzt sie historische statt rationale Kategorien“ (Salomon 1919, 20).

82 „Das liberale Bürgertum, so sagte er [Mannheim in Zürich 1928, CH], wolle in typisch intellektualistischer Weise die Irrationalität der Spannungen zwischen Verschiedendenken aus dem Wege räumen zugunsten der Einheitlichkeit der ratio, der menschlichen Vernunft. [...] Das Verständnis für Gegensätzlichkeiten der Wertungen und Ideen, die in der Gegensätzlichkeit der Seinslage ihren Grund hätten, gehe Liberalen und Demokraten ab“ (Elias 1990, 151). Zu Mannheims „Liberalismus“ siehe Kettler/Meja 1995, Endreß/Srubar 2000.

83 IISG II/744. Vgl. den folgenden Brief Benjamins an Salomon: „Es ist ganz außerordentlich erfreulich, dass Sie im Falle Mannheim eingreifen. Mich hat es längst empört, wie man ihn von Pontius zu Pilatus schickte und die Sache auf unanständige Art verzögerte. Gewiss muss auch er selber die Sache unglücklich angegriffen haben, um einen solchen Vorgang überhaupt möglich zu machen. Aber dessen Odium fällt doch auf die Heidelberger. Grüßen Sie ihn bitte herzlich“ (16.9.1924; in: Benjamin 1995 II, 493).

84 Von der Fakultät waren ursprünglich Hans Kelsen, Carl Schmitt und Leopold von Wiese als Nachfolger vorgesehen. Doch das Ministerium in Berlin setzte eine andere Liste mit folgenden Plätzen durch: „an erster Stelle Mannheim, an zweiter Stelle pari passu Salomon und Stoltenberg und an dritter Stelle Honigheim“ (Hammerstein 1989, 129). Mannheims Präsenz war auch in der Wahrnehmung anderer jüdischer Aspiranten wie Walter Benjamin oder Siegfried Landshut ein Hindernis - man ging davon aus, dass zu viele Juden an einem Institut nicht geduldet würden: „Absicht der Habilitation bei Alfred Weber. Schwierigkeiten wegen der Habilitation eines zweiten jüdischen Privatdozenten im selben Fach (neben Karl Mannheim)“ (Siegfried Landshut 1936, nach Nicolaysen 1997, 65; vgl. Benja- 
als Assistenten (diese Assistenz wurde bis 1933 formal weitergeführt), Salomon allerdings suchte fortan andernorts sein Glück, etwa an Beamtenakademien in Frankfurt und Saarbrücken (siehe dazu Salomon 1931), in Davos, Italien und Frankreich. Die Stimmung zwischen ihnen muss sich also aus verschiedenen Gründen getrübt haben. Wahrscheinlich ist, dass editorische Eingriffe Salomons an Mannheims Text dafür eine Rolle gespielt haben. Jedenfalls legt dies folgender Einschub in Mannheims berühmtestem Buch nahe:

„Die wichtigsten strukturanalytischen Feststellungen der oben stehenden Ausführungen [partikularer/totaler Ideologiebegriff, $\mathrm{CH}$ ] waren schon in dem damals der Redaktion des soeben erwähnten Jahrbuchs [!] eingereichten, aber nicht zum Abdruck gelangten Kapitel über die verschiedenen Bedeutungen des Ideologiebegriffes enthalten“ (Mannheim 1929, 56 Fn.).

Vielleicht lag es daran, dass sich Salomon plagiiert und zugleich übertrumpft gefühlt hat? Mannheim war ein ähnlich breit gelagerter Soziologe, der ebenfalls aus der Philosophie kam; er hatte mit derselben Stigmatisierung zu kämpfen (sowohl jüdisch wie auch aus einem weiterem Grunde „fremd“ zu sein: Salomon war halb französisch, Mannheim ungarischer Emigrant); zugleich habilitierte er 1925 über ein ähnliches Thema (Romantik und Konservativismus); er hatte sich wie Salomon lange mit der Mystik beschäftigt und deutete diese soziologisch ähnlich (s.o.); und er vertrat dieselbe Konzeption einer ausgleichenden Soziologie, die zwischen verschiedenen Soziologieschulen und politischen Weltanschauungen vermitteln wollte (1929). Zudem behandelten sie im Jahrbuch dasselbe Thema, nämlich die „Ideologie“ und „Politik als Wissenschaft“ (Mannheim 1929; Salomon: Jahrbuch I, 419; 1959, 249).

Diese Wissenschaft bestand darin, politische Ideologien als solche zu durchschauen, damit jedoch nicht zu denunzieren, sondern auf Ausgleich und Verständigung hinzuarbeiten, ganz im Sinne von Habermas. Gründe genug, einander zu misstrauen, gab es. ${ }^{85}$ Darum ist aus dieser erstaunlichen Parallele kein „Paarlauf“ (Hoeges 1994, 51, 98) geworden.

min an Sholem am 30.12. 1922, in: Benjamin 1995 II, 299; oder den erstaunlichen Brief Simmels an Rickert am 17. 06. 1906, Köhnke 1989, 190).

85 Ein Brief Mannheims an Salomon vom 21.2.1925 dokumentiert die Verstimmung: „Lieber Herr Doktor, Ihr Brief hat mir sehr weh getan. Er tat mir weh nicht in Folge des Inhaltes ihrer Vorwürfe [...], sondern der Form, in der Sie sie vorbrachten. Ich hatte bisher das Gefühl, bei ihnen geborgen zu sein und freute mich, dass sich zwischen uns eine Atmosphäre bildete, die eine vorbehaltslose Aussprache und dadurch eine fruchtbare wissenschaftliche Diskussion ermöglichte. Nun ist ihr Brief [...] voll Stacheln“ (IISH, IIb/744). Am 20.5.1931 beansprucht Salomon in einem Brief an Al- 


\section{Praktische Vermittlung in Davos}

„In den Hochschulen, Ämtern und Bureaus bestehen Vorurteile und Missverständnisse en masse, Affekte und Antipathien gegen das Fremde. " Salomon 1931a, S. $5 f$.

Salomon hatte in diesen Herausgaben seine Rolle als Vermittler gefunden, in der er sehr stark war, allein schon was den Output angeht. Eigene Aufsätze jener Zeit zeigen, dass dieses Talent schwer in eigenständige Texte zu übertragen war: größere Arbeiten jener Zeit, von denen es nicht viele gibt (1924 und im Jahrbuch II; meist erschienen kleinere Einlassungen und Lexikonartikel), versuchen, das Ganze des Wissens eines Gebietes zu präsentieren. Das führt dazu, dass die immerhin beeindruckende Fülle der Informationen in diesen Texten etwas konturlos und eher nacherzählend daherkommt; selten gibt es Thesen oder klare Argumentationsstrukturen, es bleibt über weite Strecken bei Nacherzählungen in didaktischer Absicht. Sein Talent war eindeutig ein anderes.

So kommt es, dass wir Salomon, als er sich von der Frankfurter Universität weg zu orientieren beginnt, ${ }^{86}$ zunächst als Lehrer treffen, und zwar an Beamtenhochschulen in Frankfurt und Saarbrücken, wo er Vorlesungen zur Staatslehre hält, die 1931 als Buch erscheinen. Bekannter geworden ist allerdings die Rolle, die Salomon bei den Hochschulkursen in Davos spielte. Diese steht im Rahmen eines breiteren außeruniversitären Engagements für die Völkerverständigung, insbesondere mit Frankreich, welches er Ende der 1920er Jahre an den Tag legt. ${ }^{87}$ Die Davoser Hochschulkurse sind inhaltlich zwar noch nicht systematisch ausgewertet worden, allerdings ist dieser Abschnitt der Leistungen Salomons am besten dokumentiert, weshalb wir uns hier kurz halten können. ${ }^{88}$

vin Johnson, der „eigentliche Begründer der Ideologienlehre in Deutschland“ zu sein (IISH, IIb/569). Der Bericht über Ausfälle Salomons (in: Endreß 2000, 131) ist mit Vorsicht zu betrachten.

86 Nach Belitz (1997b, 308), die den organisatorischen Salomon gut portraitiert, ist Salomons Umorientierung seinem verpassten Lehrstuhl, vielleicht sogar ursächlich, vorangegangen. Dies legt u.a. ein Brief Oppenheimers an Salomon vom 2.8. 1929 nahe: „Ein wenig Schuld haben Sie auch: sie haben die Herren weidlich geärgert und in der letzten Zeit doch wohl nicht so streng gearbeitet, wie es möglich gewesen wäre“ (IISH, IIb/866).

87 Einstieg war ein Gastaufenthalt in Paris 1927 (Belitz 1997b, 293, 298f.)

88 Siehe Gründer 1988; Wuchterl 1997, 137-162 (der wie Belitz viele zeitgenössische Zeitungsartikel auswertet); Belitz 1997b, 488-502; Kaegi 2002. „Da die Teilnehmer hauptsächlich aus Frankreich und Deutschland, ferner aus Italien, Niederlande, Irland, Polen, Ukraine, Litauen und der Schweiz kamen, konnte wenigstens im kleinen Kreis die schwierige Verständigungspolitik der ausgehenden Zwanziger Jahre praktiziert werden. Man verstand die Gespräche, in denen alle Fakultäten vertreten waren, aus- 
Das Konzept seiner pluralistisch-verständigungsorientierten Herausgaben wurde hier praktisch. Es ging in diesen zweiwöchigen Ferienkursen um grenzüberschreitenden Dialog, und zwar in mehrfachem Sinne: zwischen Fächern, zwischen Generationen und zwischen Nationen. In den Davoser Hochschulkursen, zu denen jeweils hunderte Studenten und viele berühmte Professoren kamen (Albert Einstein beispielsweise gab ein Benefizkonzert), ist dieses Konzept beispielhaft aufgegangen, wenn auch nur für weniger Jahre, von 1928-1931. Um die akademischen Abschließungsriten zu umgehen, benutzte Salomon einige „Tricks“ - so änderte er ständig die Sitzordnung bei Tisch, um Cliquenbildung zu vermeiden; er bat die Professoren, einige Meisterschüler mitzubringen, die er dann untereinander mischte und ähnliche Handgriffe mehr:

„Der Trick bestand darin, dass der Vorlesungsbesuch für Professoren obligatorisch war, was ich damit begründete, dass es zu einem Gespräch kommen müsse und also der Vorredner angehört werden sollte“ (Glanz über Davos, 3).

Es ist erstaunlich, wen Salomon alles in Davos versammeln konnte: allein im Jahr 1930 trafen sich dort u.a. Werner Sombart, Alfred Weber, Leopold von Wiese, Maurice Halbwachs, Hendrik de Man, Oswald von Nell-Breuning und der Faschist Guido Bortolotto. Diese Mischung deutet an, dass es hoch her gehen konnte - und die politisch aufgeladene Stimmung der Zeit, deren Verschlechterung auch das Ende der Kurse brachte, tat das Ihrige hinzu. Für Salomon eine Zeit der Bewährung:

„Aber ganz problemlos scheint dieses Unternehmen nicht abgelaufen zu sein. Die ,Neue Zürcher Zeitung، berichtet von ,Diskussionsabenden über deutschfranzösische Verständigung [...], die so gefährlich wurden, dass der nie versagende Leiter der Kurse, Professor Salomon aus Frankfurt, alle seine Gewandtheit spielen lassen musste, um Böses zu verhindern““ (Wuchterl, 143).

Salomon war also ganz in seinem Element und berichtet daher auch noch in späteren biografischen Fragmenten begeistert davon (Glanz über Davos). Auch die Kontakte, die sich hier ergaben, wurden weiter genutzt: zunächst für einen Deutsch-Französischen Arbeitskreis für Wirtschafts- und Sozialpolitik, der politisch wegweisende Konzepte wies, indem er auf wirtschaftliche Zusammenarbeit, direkten Austausch und den Abbau von Vorurteilen setzte (Belitz 1997, 288-291, 300 f.), ${ }^{89}$ dann

drücklich und primär als Versuch der Aussöhnung zwischen französischer und deutscher Intelligenz; vom ,Locarno d'intelligence“ war gar die Rede“ (Wuchterl 1997, 142).

89 Hier mag erneut das Vorbild des inzwischen ermordeten Rathenau gewirkt haben, auch eine Nachwirkung von Bubers Dialogik ist denkbar. 
aber auch in Salomons Pariser Exil seit $1933 .{ }^{90}$ Interessant für uns ist vor allem das Selbstverständnis, mit dem Salomon die Kurse angeht. Salomon möchte einem rein geistigen Gespräch entgehen, für welches es genügen würde, ein Buch über das andere Land zu lesen - ein Seitenhieb auf die zeitgenössische Frankreichkunde von Ernst Robert Curtius, Arnold Bergsträsser oder Friedrich Sieburg:

„Es genügt nicht, über Verständigung zu reden und das ,Wesen“ oder den ,Geist' des anderen Volkes oder seine Geschichte darzulegen, man muss diese Geister aufeinander wirken lassen, dass sich eine Vermittlung ergibt, und dass die Möglichkeiten und Mannigfaltigkeiten Deutschlands und Deutschland im concours des idées sich verwirklichen. Zusammenarbeit ergibt sich sicher, wo Menschen, auch wenn die Standorte sie trennen, als aktuelles Ziel die Zusammenarbeit an einem größeren Ganzen anerkennen und sich von Illusionen und Traditionen befreien“ (Salomon 1931a, 8, Hvg. CH; vgl. Belitz 1997a, 59).

Dennoch gibt es einen leichten Elitismus dabei - den Elitismus der Mittelklasse. Salomon arbeitete an einer Soziologie der Intelligenz, welche er als primäre Trägergruppe des Nationalismus ansah. Diese Multiplikatoren wollte er erreichen, die ,staat- und kulturtragenden Schichten, der Beamten, Lehrer wie der Wirtschaft und Juristen“ (1931a, 7). Vielleicht ist es dieser Adressatengruppe geschuldet, dass er nicht mehr die im Ganzen eher unbeliebte Soziologie in den Vordergrund stellte, die er noch 1926 als ausgleichende Plattform in Anspruch nahm, ${ }^{91}$ sondern nun vielmehr die mit mehr Prestige ausgestattete Philosophie. ${ }^{92}$

90 Zu den späteren Förderern gehörten André Siegfried und Célestin Bouglé.

91 „Die Hochschulen werden ihren Einfluss erst wieder gewinnen, wenn sie [...] die Universalität, welche die Philosophie einmal besaß, wiedergewinnen. Die neue Richtung, die diese Universalität anstrebt, führt den Namen ,Soziologie““ (Jahrbuch I, 2). Dass Salomon die vermittelnde Instanz durchaus nicht fixiert hatte, zeigt folgende Bemerkung seiner Staatsvorlesung: „Der Staat wird gleichsam in der Person des Beamten populär, der als Vermittler [!] mit Verantwortung und Verpflichtung gegenüber der Gesamtheit den direkten Zusammenhang von Staat und Gesellschaft herstellt. Gerade in einer Zeit der Auseinandersetzung von Staat und Gesellschaft ist eine neutrale Instanz notwendig, um die Ordnung zu halten“ (Salomon 1931, 65). Das ist gut hegelianisch und vor allem gegen Schmitt gewandt, der Neutralität perhorreszierte. Allerdings widerläuft es der Absicht, statt normativer Ideen den „wirklichen Staat“ zu zeigen (1931, Vorwort), denn viele Beamte waren damals parteiisch.

92 „Wie die Abschließung der Fächer und Gebiete des Geistes, so muss auch die der Gruppen und Länder durch wiederholte Veranstaltungen von Kongressen zwischen den Ländern und Fächern aufhören. Es ist die Aufgabe der Philosophie [!], diese neue Diskussion und Kooperation zu führen. Sie muss als Geist der Zeit nicht nur Religion und Kunst, sondern vor allem Staat und Wirtschaft einbegreifen“ (Salomon 1930a, 565). 
Zwei hochkarätige Philosophen haben die Davoser Hochschulkurse denn auch berühmt gemacht, da ihr Aufeinandertreffen hohe Wellen schlug - Ernst Cassirer und Martin Heidegger. Der Streitpunkt zwischen ihnen in Davos 1929 zeigt in doppelter Hinsicht auf, woran der Verständigungsgedanke letztlich scheiterte. Martin Heidegger verweigerte den Dialog schon persönlich: er war - von Profilneurosen sicher nicht ganz frei, denn gerade damit kam er gut an - auf Konfrontation aus (Wuchterl 1997, 146 f.), obwohl die Themenstellung sehr geschickt „über Kreuz“ gelegen hatte: Cassirer referierte über Anthropologie, Heidegger über Kant, also jeder über das Thema des anderen.

Aber es war nicht nur der persönliche Stil Heideggers, auch seine sehr deutsche Philosophie verunmöglichte einen solchen Dialog: Cassirer suchte einen Weg, Dialogfähigkeit „transzendental“ zu begründen, und seine Philosophie der symbolischen Formen (1923-29) war ein Weg dorthin - sind doch Symbole ein eminentes Verständigungsmedium. Heidegger dagegen schnürte den Raum des Menschen derart eng („Auch die Transzendenz bleibt noch innerhalb der Geschöpflichkeit, der Endlichkeit“, Heidegger GA 3, 279), dass Selbstdistanz unmöglich wird:

„Was in Heideggers Analysen als Räumlichkeit in den Blick kommt, ist solch ein bloßer Aktionsraum wie der des Tieres. Dem hält Cassirer entgegen, dass den Menschen doch vom Tier die Fähigkeit unterscheide, Distanz zu nehmen, sich die Dinge gegenüber zu stellen [...] Ist nicht das Vermögen zur Distanzierung ein konstitutives Moment der Freiheit des Menschen?‘93

Hier wird gleichsam vorgezeichnet, aus welchen Gründen der Dialog abbrechen musste: nicht nur der jeweilige Dialogpartner (hier Cassirer) wurde nicht mehr geduldet, schon der Gedanke eines Austausches (und damit auch sein Organisator) wurde abgelehnt (vgl. Fn. 57). Beide, Cassirer wie Salomon, flohen wenig später ins Exil. Das Konzept einer ausgleichenden Instanz hatte somit einstweiligen ausgespielt; das „Selbstbehauptungs“-Denken Martin Heideggers und Carl Schmitts, das nur Freund oder Feind, aber weder Dialog noch Neutralität kennt, obsiegte.

93 Gründer 1988, 296. Vgl. Karl Mannheims Heideggerkritik: auch der Existentialphilosoph sei reflexiv: „Er will sich dazu nur nicht bekennen“ (1930, 71). „Man entdeckt, dass etwas vollständig reflexiv ist und entdeckt gleichzeitig, dass es einmal einen direkten Aktvollzug gab und schwärmt für diesen Akt, aber ohne konkreten Gehalt“ (1930, 77; ähnlich König 1937; Henning 2005, 302-320, siehe Barboza in diesem Band). 


\section{Exil in Frankreich}

Salomons erfolgreichste und ertragreichste Zeit neigte sich damit dem Ende zu. Er, der seit 1932 ohnehin in Italien weilte, floh 1933 weiter nach Paris. ${ }^{94}$ Aufgrund seiner Kontakte scheint er dort zunächst relativ gut unterzukommen, er gibt Zeitschriften wie die Information Economique (1933) und später Ordo (1938) mit heraus, berät das Außenministerium und hatte Lehraufträge in Paris. ${ }^{95}$ Auch arbeitete er in Emigrantenorganisationen wie dem Lutetiakreis oder der „Volksfront“ mit. ${ }^{96}$ Zwar war ihm die Mitarbeit an Horkheimers Zeitschrift weitgehend verwehrt, wahrscheinlich durch Invektiven Adornos. Dieser sprach sich offen gegen eine Beteiligung Salomons an der Institutszeitschrift aus, die für viele Emigranten eine wichtige Einkommensquelle war:

„Salomon gab mir ein Separatum eines Aufsatzes über Wissenssoziologie; der Mann ist für uns, wäre es selbst als kleinster Mitarbeiter des Besprechungsteils, völlig untragbar“ (Adorno an Horkheimer, 7.8.1937). ${ }^{97}$

Anders als viele andere Emigranten kann er allerdings Aufsätze in fran-

94 Ein Telegramm aus Berlin nennt ihn zuerst: „Bis zur endgültigen Entscheidung aufgrund des Beamtengesetzes sind mit sofortiger Wirkung unter Entbindung von allen Universitätsverpflichtungen beurlaubt die Professoren Salomon, Mennicke, M.Wertheimer“ etc. (24.4.1933, UAF, Abt. 4, Nr. 134, Kultusministerium an das Frankfurter Universitätskuratorium).

95 Nach Otthein Rammstedt diente Salomon als Berater für das Verhalten gegenüber Deutschland und flog in dieser Eigenschaft etwa nach London. Ein Lebenslauf, mit dem Salomon 1941 in den USA aufwartet (und zu diesem Zwecke sicher etwas hochpoliert war), gibt folgende Ämter in Frankreich an: „Lecturer, Institute of Germanistic Studies, University of Paris 1936-39. [...] Director, Economic Bulletin for Central Europe (Foreign Office of France) Paris, 1933-36. Member, Documentation Office, Musée de la Guerre, Paris, 1937-38. Boursier, Rockefeller Foundation, Paris, 193739 for special studies on public administration in Germany and France“ (Emergency Committee Records, Mss. \& Archives Section, New York Public Library, box 91).

96 Schiller 1981, 86, 90 f., 521f.; vgl. dazu Langkau-Alex 2004.

97 Adorno/Horkheimer 2003 II, 394 (es ging wohl um das Thema „Comte ou Hegel“, das Jahrzehnte später von Oskar Negt traktiert wurde; vgl. schon Georg Mehlis in Salomons Jahrbuch III, 91-110). Adorno überreichte Horkheimer auch eine „Liste von Namen [...], deren kritische Mitarbeit mir unmöglich erscheint (wohlverstanden: sachlich; die Frage der taktischen oder privaten Notwendigkeit, sie heranzuziehen, lasse ich dabei ganz außer Betracht). Es handelt sich dabei um“, und nun fallen u.a. die Namen Honigsheim, Marck, Tillich und Salomon (15.12.1936; 2003 I, 262). 
zösischen Fachjournalen unterbringen. ${ }^{98}$ Um sich in Paris akademisch zu etablieren, musste Salomon jedoch offenbar noch eine „thése“ einreichen. Er lebte daher zurückgezogen. ${ }^{99}$ Natürlich konnte daraus nichts werden, als die Deutschen Frankreich besetzten. Auch wenn über seine genauen Lebensumstände bis 1941 wenig bekannt ist, ${ }^{100}$ lassen seine Schriften eine bemerkenswerte Wendung erahnen: je ernster die Verhältnisse werden, desto mehr verlässt Salomon seine vermittelnde Position. Er bekennt Farbe und wird kämpferisch; und er tritt offen als jüdischer Autor auf. Diese Wendung tritt bereits 1932 ein, noch vor Hitlers Machtantritt - zunächst in einer scharfen Abfuhr an Carl Schmitt, den er persönlich kannte und noch kurz zuvor als anregende Quelle angeführt hatte (1931, Vorwort). ${ }^{101}$ Ebenfalls im Jahr 1932 verändert Salomon seine Adressaten: er wendet sich nicht mehr in der Hoffnung auf Ausgleich an eine Allgemeinheit, sondern, resigniert und trotzig zugleich, „wende ich mich [...] an Juden, und zwar an den Einzelnen“ (1932a, 260).

Worum geht es ihm? Salomon möchte die Juden über ihre höchst brisante Lage aufklären. Dazu gehört einerseits die Warnung vor einer Politik, die sich gegen den „,inneren Feind“ richtet $(1932,256)$ und die absolutistisch zu werden droht; andererseits vor dem Antisemitismus. Dieser ist nach Salomon nicht aus Religion, Rasse oder Reichtum der Juden zu erklären (1932a, 268), sondern aus einem sozialpsychologisch

98 Eine ausführliche Bibliographie befindet sich in Salomon 1965, 718-730.

99 Benjamin schreibt Fritz Lieb am 31.12.1937, er habe Salomon „nicht oft gesehen. Es ist gänzlich von der Arbeit an seiner thése über den Kathedersozialismus in Anspruch genommen“ (Benjamin 1995 V, 638). Von einer „thése“ ist auch in einem Schreiben an die Universität Frankfurt die Rede, in dem er erfolgreich um eine Bestätigung seiner akademischen Grade bittet: „Da ich an der Universität Paris das Doktorat zu erwerben gedenke, benötige ich die genannten Diplome und wäre für die Übermittlung dankbar“ (30.1.1937, Rektoratsakte UAF, Abt. 4, Nr. 123, Bl. 11).

100 Carola Dietze verdanke ich den Hinweis auf eine Kooperation mit Plessner, der jedoch Reserven hatte: „Er ist gewiss gutartig, gehört aber auch dem Reichsverband vereidigter Hühneraugenvertreter an und kann viel verderben“ (Plessner an Pos, 17.12.1935, UB van Amsterdam XXXIII, nach Dietze 2006, 126). Zur französischen Soziologie Moebius 2006.

101 Salomon 1932 korrigiert Details, verteidigt den föderalen Pluralismus und die Neutralität des Staates und warnt vor „Absolutismus“. Schärfer fällt die Kritik 1938 aus. Allerdings sind beide Polemiken nicht wirklich luzide, Salomon verheddert sich in Details. Er wirft Schmitt eine Ähnlichkeit mit Adam Müller vor (1938, 184), was man nur versteht, wenn man die Hintergründe kennt. Bereits Löwith (1935) hatte diesen Punkt prägnant formuliert. Zu Schmitts Tagung „Das Judentum in der Rechtswissenschaft“ meint Salomon: „Gerade die Vorträge der Breslauer Tagung beweisen unumstößlich, was die deutsche Rechtswissenschaft den Juden verdankt und sind ein Eingeständnis eines Gefühls geistiger Minderwertigkeit“ (1938, 188; cf. Gross 2000, 120 ff.). 
zu erklärenden Fremdenhass seitens der Deutschen. Diese Position ist nicht neu (Salomon verweist auf Oppenheimer und Fritz Bernstein).

Sie beißt sich allerdings ein wenig mit seiner schon zuvor (1920a) formulierten Assimilationskritik: „Die sogenannte Emanzipation ist teuer bezahlt worden, indem der einzelne Jude mit dem Glauben an sich und seine Sendung gebrochen hat“ (1932a, 268). Die Antwort auf einen Fremdenhass könnte ja im Sinne Rathenaus auch eine radikale Assimilation sein. Aber genau die hat nach Salomon nicht gegriffen, die Fremdheit der Juden blieb, zum Preis einer inneren Schwächung:

„Ein inneres Ghetto und eine Vorstellung von Paria sind irgendwie geblieben. Die bürgerliche Emanzipation hat auch bei den Juden einen Willen zum sozialen Aufstieg hervorgerufen, aber das Parvenütum erhielt eine spezifisch jüdische Note“ (Salomon 1932a, 267).

Ähnlich wie Hannah Arendt geht es Salomon hier um jüdische Selbstbehauptung, die allerdings nicht antiassimilatorisch, nicht antimodern und nicht notwendig zionistisch sein muss - Salomon fordert mit anderen Worten eine jüdische Renaissance im Sinne Franz Rosenzweigs. Die Juden sollen sich auf modernem Boden neu finden und behaupten.

Dieses Programm von 1932 verfolgt Salomon im Pariser Exil offensiv (ob es Kontakte zu Hannah Arendt gab, ist offen). Mit Siegfried Thalheimer (nicht zu verwechseln mit dem Kommunisten August) gründete er im Jahre 1938 das Comite Juif d'Etudes Politiques, eine Vereinigung, die unter den Emigranten für jüdische Selbstbesinnung eintrat und zu diesem Zwecke die deutschsprachige Zeitschrift Ordo herausbrachte. Es begriff sich als ein Weckruf und kritisierte das defensive jüdische Auftreten. Wofür genau dieses Komitee stand, was also der Inhalt der Selbstbehauptung sein sollte, war nicht ganz durchsichtig. ${ }^{102}$ Walter Benjamin zieht am 1.5.1938 Karl Thieme zu Rate, um es zu bewerten:

„Ist Ihnen die Zeitschrift Ordo vom Comité juif des études politiques, 22 rue Caumartin Paris IX zu Gesicht [ge]kommen. Was die Leute wollen, scheint mir noch ungeklärt. Von ihrer Kritik am öffentlichen Auftreten und an den öf-

102 Selbst ein internes Papier gibt darüber keine Auskunft: „Nicht der Antisemitismus sei das eigentliche Unglück, sondern die offenbare jüdische Unfähigkeit, sich selbst zu behaupten“ (Thalheimer 1938, 1). Doch wie? Nach Meinung des Komites durch „Ausbau der Theorie“ (1), mit dem Ziel der Bildung eines „gesamtjüdischen Bewusstseins“ (2) und einer „alljüdischen Politik“ (3). Worin die bestehen sollte, bleibt an dieser Stelle offen. Darin gleicht dieses Engagement übrigens der kritischen Theorie, die offensiv auftrat, aber keine positive Ziele formulieren mochte und dafür das alttestamentarische Bilderverbot in Anspruch nahm. 
fentlichen Reaktionen der Juden will mir scheinen, dass sie häufig den Nagel auf den Kopf trifft. Ich wollte, Sie würden der Sache ansichtig und teilten mir ihre Meinung von ihr mit“ (in: Benjamin 1995 VI, 72).

Die Schriften, die Salomon in Ordo beiträgt, sind ganz im Sinne dieser Bewusstmachung gehalten. Auf verschiedene „Vorläufer“ des Antisemitismus wird hingewiesen, und als besonderes Übel gilt die Entzweiung zwischen deutschen Juden und dem „Einwandererstrom des Ostjudentums“ (1938b, 15). Deutlicher wird Salomon nur in einer anonymen Schrift, deren Titel Programm ist: „Keine Rettung ohne Judenstaat“ (1938a). Diese Schrift lässt erstaunen. Sie beginnt mit einem hellsichtigen Donnersatz, der die „planmäßige Vernichtungspolitik des Dritten Reiches, deren Opfer die deutsche und die österreichische Judenschaft sind“, klar benennt (1938a, 3). Auch eine Lösung wird offensiv vorgegeben - durchaus untypisch für Salomon. Es ist nicht nur der Glaube an die (inhaltlich unbestimmte) eigene Kraft, sondern ein konkretes Ziel:

„Kein Volk wird zu außerordentlichen Anstrengungen und Opfern bereit sein, wenn es nicht von seinem eigenen Wert, von seiner Idee überzeugt ist. [...] Daher gibt es außerhalb des politischen Zionismus, der alle Juden durch die Gründung eines Staats befreien wollte, keine Rettung“(1938a, 5).

Es geht um die Idee eines jüdischen Staates als Klammer um die Judenheit, die sie organisatorisch einigen und innerlich stärken soll. Ist das nun ein Bekenntnis zum Zionismus? Durchaus nicht, zumindest nicht zu den zeitgenössischen Zionisten. Diese nämlich werden vordringlich kritisiert, sowohl die kulturzionistische Fraktion, zu der Martin Buber und Franz Oppenheimer gehört hatten, wie auch die politischen Zionisten, da sie auf das falsche Pferd setzten - auf die Nation statt auf den Staat. ${ }^{103}$

Ob dieser Unterschied bedeutend genug war, um einen innerzionistischen Konflikt zu riskieren (welchen der Aufsatz eigentlich beenden

103 „Die Idee der Nation, mit der der Zionismus sich legitimiert, hat keine ordnende, formende und schöpferische Kraft. Diese besitzt allein der Staat“ (Salomon 1938a, 6). „Diese Lage [die britische Schutzherrschaft, $\mathrm{CH}$ ] ist nicht zuletzt verschuldet durch das Unverständnis der heute noch führenden Zionisten für die alles andere überragende Bedeutung der Staatsidee. Sie haben sich verführen lassen von der kulturzionistischen Irrlehre, von dem Traum einer Erneuerung des Judentums in Zion, der ihnen die Sorge für die wirkliche Judenheit abnahm“ (5). An die große Bedeutung einer „Staatsidee“ glaubte zumindest anno 1935 auch Helmuth Plessner (siehe Dietze in diesem Band). Auch Siedlungen in anderen Erdteilen werden harsch abgelehnt (4f.). 
wollte, dafür aber zu aggressiv gestimmt war), ${ }^{104}$ ist schwer einzuschätzen. Der Text ist jedenfalls ein beeindruckendes Dokument für eine Entschlossenheit, dem katastrophalen Lauf der Dinge irgendwie entgegenzuwirken, auch wenn das aufgewiesene Ziel kaum klarer ist als das kritisierte. ${ }^{105}$ Es geht zunächst primär um das Wiedererringen von Stolz. ${ }^{106}$

Reaktionen sind leider keine bekannt; was daran liegen mag, dass es wenige gegeben hat. ${ }^{107}$ Das mag auch ein Grund dafür sein, dass es Salomon bei alledem nicht wirklich gut ergangen sein kann, wie folgender Brief Benjamins an Horkheimer vom 13.3.1939 andeutet:

„An der jämmerlichen Existenz von Salomon, der ganz andere Qualitäten als ich besitzt, um sich bei den oberflächlich Interessierten ins Licht zu setzen, habe ich einen Begriff von der gänzlichen Apathie, in der die akademisch Befugten sich hier gefallen, wahrscheinlich weil jede Art des Eingreifens nur ihr schlechtes Gewissen beleben müsste“ (Benjamin 1995 VI, 232).

Salomon floh dann vor den Deutschen nach Südfrankreich und bemühte sich um eine Ausreise in die USA. Die Umstände waren hart, wie sich aus den wenigen Akten erschließen lässt. Was genau er tat, ist unsicher, möglicherweise war er kurze Zeit Soldat. Die Umstände lassen sich aber an Parallelen erahnen - etwa an Albert O. Hirschmans mutiger Tätigkeit in Südfrankreich, der mit Varian Fry zusammenarbeitete (Lepenies 2004). Mit diesem Kontaktmann des Emergency Rescue Committee und der New School in Paris dürfte auch Salomon zu tun gehabt haben.

104 Salomon nennt seine Dialogpartner „Träumer“, unterstellt ihnen „Kurzsichtigkeit“, „Trägheit“, ja „Stumpfheit“, „feige Selbsttäuschung und Dummheit“ und „krampfhaft verschlossene[n] Augen“ (1938a, 3).

105 Vergleichbar ist das Manifest Hans Jonas’ von 1939 (in ders: 2005, 186199). Jonas war 1929 übrigens auch bei Karl Mannheim (2005, 124 f.).

106 Das Ziel ergibt sich aus Salomons Überzeugung, jede Politik beruhe auf einem Glauben $(1938,174)$. Am Anfang muss daher der Glaube an sich selbst stehen: „Was nottut ist die Beseitigung der Anarchie [...] Die vielfach zersplitterte und jämmerliche Bittstellerei bei den Regierungen lässt das jüdische Volk noch elender erscheinen, als es wirklich ist [...] Nur eine starke Bewegung mit umfassenden Zielen kann die Judenheit würdig vertreten“ (1938a, 5).

107 Nach Thalheimer $(1938,3)$ gingen die Verkaufszahlen stark zurück, Ordo musste nach 8 Monaten eingestellt werden. Über Salomons finanzielle Lage gibt es wenige Daten; anfangs unterstützte ihn das Comité des Savants. 


\section{Exil in den USA}

Salomon hat sich lange bemüht, in die USA ausreisen zu können; mit der Besatzung Frankreichs wurde das zu einer Überlebensfrage. ${ }^{108}$ Ein reguläres Rockefellerstipendium wurde ihm versagt, er musste daher auf persönliche Netzwerke und das „Emergency Rescue Committee“ zurückgreifen. ${ }^{109}$ Im Januar 1941 gelingt es Salomon endlich, mit seiner Frau nach New York zu fliehen. ${ }^{110}$ Die erste Anlaufstelle war die New School for Social Research, die sich nach der Besatzung Frankreichs gerade für die Aufnahme einer zweiten akademischen Emigrantenwelle stark machte (Rutkoff/Scott 1986, 128-152; Krohn 1987). Salomon hatte bereits in Frankfurt mit Alvin Johnson kooperiert und mehrere Artikel für dessen Encyclopaedia of the Social Sciences beigetragen. ${ }^{111}$ Nun erhielt er ein zweijähriges Rockefellerstipendium für die New School.

108 „He was forced to use different names and addresses when he fled to Southern France. It is advisable to be very careful when getting in contact to him“ (Exilarchiv der Deutschen Bibliothek Frankfurt, Bestände G. Salomon, Brief von Viktor Polzer an Hermann Broch, ca. 1940).

109 Zur Organisation Krohn 1987, 32 ff. Hermann Broch schreibt am 29.10. 1940 an Wolfgang Sauerländer: „ich habe schon wieder zwei Schützlinge ans Herz gelegt bekommen, der eine ist der bekannte Soziologe Gottfried Salomon, der andere der katholische Philosoph Balduin Schwarz. Beide sind hochgefährdet, Salomon musste in Frankreich unter falschem Namen leben, während Schwarz in der französischen Armee kämpfte, also Hochverräter ist; beide sind jedoch von der Rockefeller Stiftung abgelehnt worden, sodass sie nicht auf Professorenvisum herüberkommen können, man muss ihnen also Affidavits verschaffen und sie ins Rescue Committee geben“ (Exilarchiv Frankfurt, Bestände Gottfried Salomon). Weitere Akten zu Salomon finden sich in der New York Public Library, Manuscript Division, „Emergency Committee in Aid of Displaced Foreign Scholars“, unter der Rubrik: „Correspondence with and about scholars who did not receive grants or fellowships“ (dazu gehört auch Hannah Arendt; die Broch später ein Denkmal setzt, 1968, 111-153).

110 Nach einem Bericht von O. Rammstedt sei man mit einem U-Boot auf einen amerikanischen Frachter entkommen. Als Salomon dann Mitglieder des Institutes für Sozialforschung in Amerika traf, habe er anlässlich ihrer Versuche, sich auf Englisch zu verständigen, vorgeschlagen, da man untereinander sei, könne man ja Jiddisch reden. Auf solcherlei Scherze war besonders Adorno nicht gut zu sprechen, auch wenn er „jüdische“ Wurzeln des Kritischen Denkens später nicht ungern hervorhob.

111 Neben „Hero Worship“ und „Social Organism“ waren die meisten Artikel biografisch (über Franz von Baader, Edmond Demolins, Arthur de Gobineau, Frédéric le Play, Carl Müller-Lyer, Gustav Ratzenhofer, Lorenz von Stein und Ludwig Stein; siehe Salomon 1965, 725 sowie der Briefwechsel mit Alvin Johnson darüber von 1931-33, IISH, IIb/569; Salomon schrieb übrigens seinen Briefpartner, auch Johnson, meistens auf deutsch). 
Diese konnte allerdings unmöglich alle „displaced scholars“ langfristig behalten, vielmehr verstand sie sich als Anlaufstelle zur Weitervermittlung der angekommenen Exilanten an reguläre akademische Stellen. Einen solchen Versuch unternahm man auch mit Gottfried Salomon. Wenngleich seine Lebensdaten in Lexika reguläre Stellen angeben (Fn. 5), sprechen die Akten eine etwas andere Sprache. Ein Ausflug nach Denver, von dem sich insbesondere Alvin Johnson viel versprochen hatte, da er Salomon dort am neu zu gründenden Institute for Advanced Studies unterbringen zu können hoffte, hatte nicht den erwünschten Erfolg. Aus der Wahrnehmung der Amerikaner hatte Salomon Schwierigkeiten, sich an das akademische Leben in den Vereinigten Staaten anzupassen. ${ }^{112}$ Das galt zwar nicht nur für Salomon (Luckmann 1981, Jay 1986), im Unterschied zu seinen ehemaligen Frankfurter Kollegen vom Institut für Sozialforschung hatte er allerdings keine eigenen Mittel, um sich eine Distanz leisten zu können. Salomon hatte in Amerika zwar Kontakte, die auf seine Frankfurter Zeit zurückgingen; etwa zu Louis Wirth in Chicago, der möglicherweise sogar über Salomons „thése“ verfügte. ${ }^{113}$ Diese Kontakte führten allerdings laut Bernsdorf 1980 erst wieder 1946 zu einer Anstellung als „Visiting Lecturer“ bei der Columbia University (so die Titulierung in Salomon 1948, 220).

Möglicherweise war Salomons Selbstverständnis in der Zwischenzeit nicht mehr primär eines als akademischer Soziologe, sondern als praktischer Spezialist für Verwaltung und Organisation. Er hatte mit seiner

112 Laurens H. Seelye, der mit in Denver war, schreibt am 5.2.1942 an Johnson: „In the opinion of all of us he needs some continuing close contact with an American community so that he can come to understand 'the American point of view'. It is not very easy for him to inquire as to the good work which is already being done in an academic community, show his appreciation of it, and then link his own ideas to it. [...] We all felt that Dr. Salomon could talk to a broad minded person with an understanding of foreigners [...] But if someone like a news reporter or an American legionnaire, or any garden-variety patriot talked with Dr. Salomon he might go away with a disastrous impression" (New York Public Library, Manuscript Division, Emergency Committee Records, Box 91: Gottfried Salomon). Auch gibt es Unmut darüber, dass Salomon zu reichlichen Gebrauch von der Gastfreundschaft macht (er nahm seine Frau mit), man wird ihm insgeheim eine intellektuelle Arroganz vor.

113 Eine Beschreibung Salomons, die vor seiner Ankunft im Committee zirkulierte, gibt an: „Salomon's latest work is a 1000 page study of the German bureaucracy under Wilhelm. This manuscript was saved when Salomon fled Paris and is now at the University of Chicago“. Wirth lobte Salomon ,as the most competent interpreter of the development of geographical and social institutions in their relation to the cultural and economic institutions and ideas at various stages in the history of Western Europe“ (Emergency Committee Records, Box 91, ca. 1940). 
Zeit bei Rathenau und in den Verwaltungsakademien, mit den Davoser Kursen und der Frankreichakademie in der Tat einige Erfahrungen vorzuweisen. In der Kriegszeit hat Salomon dann auch als Berater für die Regierung gearbeitet, als Spezialist für das französischsprachige Nordafrika (Algerien, Marokko und Tunesien). ${ }^{114}$ In seinen Schriften schlägt sich die Zeit in den USA und seine Tätigkeit für die Administration allerdings kaum nieder, er veröffentlicht lediglich zwei Aufsätze, die ältere Ideen einem amerikanischen Publikum neu präsentieren (1948). ${ }^{115} \mathrm{Er}$ arbeitete somit nicht, wie viele andere Emigranten, an Faschismus- oder Wiederaufbautheorien (Löwenthal 1979, Söllner 1982, Krohn 1987). Jedenfalls treten keine vergleichbaren Texte ans Licht.

Die Bemerkungen späterer Schriften lassen ebenfalls keine prägende „Amerikaerfahrung“ erkennen, wie sie etwa für die kritische Theorie oder für Hannah Arendt so wichtig waren. ${ }^{116}$ Zwar äußert er sich positiv über die USA und deren politische Form (vor allem in 1959, 233-248), doch diese Westbindung war lange vorher gegeben - beispielsweise war er schon in den 1920er Jahren Mitglied der American Sociological Association und gab mehrere amerikanische Werke heraus (etwa von Harry Elmer Barnes oder Charles Ellwood, beides 1927). Salomon war und blieb jedoch ein Gelehrtentyp der alten europäischen Schule. ${ }^{117}$ Seine 17 Jahre in den Vereinigten Staaten sind bislang nur wenig nachvollziehbar.

114 Mündliche Mitteilung von Otthein Rammstedt.

115 Daneben hat Salomon nach Auskunft von Günther Roth eine amerikanische Ausgabe von Lorenz von Stein mitbetreut (Stein 1964).

116 Siehe Claussen 1999 sowie Schulz in diesem Band. Der späte Salomon beklagt in einem Einschub zur nordamerikanischen Staatslehre die „,blinde[n] Nachahmung populärer Methoden einer empirischen Forschung, welche wesentlich kommerzielles Interesse hat und deshalb sich politisch mit der öffentlichen Meinung vor allem beschäftigt“ $(1965,691)$. „Wer in bloß statistischen oder psychologischen Untersuchungen des gegenwärtigen Alltags stecken bleiben will, lässt eine Apathie erkennen, die sich dem status quo ohne jeden Versuch einer Bewertung ergibt“, so Salomon in Oppenheimer 1964a, 350 f.). Im Positivismusstreit hat Adorno bekanntlich eine ähnliche Skepsis vertreten. Den Positivismus hatte Salomon - Adornos Lehrer - bereits in den 1920er Jahre kritisiert (1922, 121123; Bousquet 1926, 2; 1965, 654 f.). Zum Amerikabild dieser Generation Kamphausen 2002.

1171957 lobt Preiser an Salomon, „dass die von ihm vertretene Richtung der Soziologie an eine lange Tradition anknüpft und ganz und gar europäisch ist, im Gegensatz zu der inzwischen aus Amerika herübergekommenen empirischen Soziologie. Man braucht auch diese, gewiss, aber ein großer Teil, wenn nicht die Mehrzahl der führenden deutschen Soziologen bedauert, dass die alte Fragestellung so sehr zurückgedrängt worden ist, und in eben diesem Bedauern kommt ja zum Ausdruck, dass man solche Menschen wie Salomon gebraucht hätte“ (UAF, Akte BZ: 256, LZ: 1928-79; cf. Abt. 4, Nr. 123, Bl. 37). Doch kann man das Fehlen eines Hauptwer- 


\section{Remigrant in Frankfurt}

Es überrascht also nicht, dass Salomon sich in den 1950er Jahren um eine Remigration an seine alte Frankfurter Heimatuniversität bemüht. 1954 hält er hier eine erste Gastvorlesung. Der normale Weg - auch das vielleicht typisch für Salomon - war ihm allerdings versperrt: 1954 wird sein Antrag auf Wiedergutmachung (über welche auch Adorno zurückgekommen war) negativ beschieden; vermutlich deswegen, weil Salomon die Antragsfristen versäumt hatte. Salomon klagt - und bekommt nach vier Jahren Recht. 1958 ergeht an ihn ein Wiedergutmachtungsbescheid, der ihm u.a. Emeritenbezüge zugesteht. Der fast 66jährige sieht das allerdings nicht als Altenteil, sondern strebt nach einer Möglichkeit, in Frankfurt weiterhin zu lehren. Davon sind einige Kreise in der Universität allerdings nicht angetan und versuchen aus nicht erfindlichen Motiven nach Möglichkeit, Salomon Steine in den Weg zu legen. Am 28.11.1957 schreibt der Rektor der Universität beispielsweise folgende Zeilen an das Hessische Ministerium für Erziehung und Volksbildung:

„Bei Vollzug der Wiedergutmachung bitte ich [...] eine Form zu finden, die es vermeidet, dass Herr Salomon-Delatour Emeritus in der hiesigen Wirtschaftsund Sozialwissenschaftlichen Fakultät wird.

Herr Salomon-Delatour hat seit seiner Emigration - also seit fast 25 Jahren seine wissenschaftliche Arbeit im wesentlichen abbrechen müssen. Er würde daher kaum in der Lage sein, jetzt wieder voll im Lehrbetrieb tätig zu sein [...] Die Errichtung eines neuen Lehrstuhls für Soziologie ist seit Jahren beantragt und die Fakultät hofft, dass er im kommenden Etatsjahr bewilligt wird. [...] Es wird nun nach den mir zuteil gewordenen Informationen u.U. schwierig sein, einen geeigneten Gelehrten hierfür zu gewinnen, wenn dieser damit rechnen muss, dass neben ihm Herr Professor Salomon-Delatour, der eine außerordentlich aktive Persönlichkeit ist, steht. So wie die Dinge liegen, könnte die Ernennung von Herrn Salomon-Delatour in der Frankfurt Fakultät daher den geplanten und allerseits als begrüßenswert anerkannten Wiederaufbau der Soziologie im Rahmen der Wirtschafts- und Sozialwissenschaftlichen Fakultät erheblich hemmen“ (UAF, Rektoratsakte, an das Hess. Ministerium für Erziehung und Volksbildung, z. Hd. V. Herrn Oberreg.Rat Fröhlich, Wiesbaden).

Der Streit zieht sich erneut über Jahre hin. Besonders die Professoren Napp-Zinn und Geißendörfer setzten sich dagegen ein, dass Salomon der wirtschafts- und sozialwissenschaftlichen Fakultät als Emeritus angegliedert wird bzw., als dies nicht mehr zu verhindern war, dass er im

kes (s.o., Fn. 74) auch „amerikanisch“ deuten: „Nicht im großen Werk findet Rationalität in Amerika Ausdruck, sondern in Rede, Artikel und Lebensregel“ (Münch 1986, 364, vgl. 721 ff.). 
Vorlesungsverzeichnis erscheint. ${ }^{118}$ Salomon hat in diesen späten Jahren in Frankfurt unter den Studierenden und Kollegen aber auch einige Anhänger gewonnen, ältere Bekanntschaften ließen sich aktualisieren. ${ }^{119}$ Diesmal setzt sich auch Adorno für Salomon ein. ${ }^{120}$ So erscheinen sogar noch drei Bücher von Salomon (1959, 1965, Saint-Simon 1962). Es gab dann eine Überlegung, dass Salomon an der neu gegründeten Universität Konstanz ein Institut für Sektenforschung leiten sollte, immerhin war Salomon noch ein Schüler von Ernst Troeltsch. ${ }^{121}$ Salomons Tod kam dem allerdings zuvor; er ereilte ihn kurz vor der 100-Jahr-Feier MaxWebers, nachdem er in Jerusalem an einer solchen Feier zu Ehren Franz Oppenheimers teilgenommen hatte.

Nach Salomons Tod im April 1964 erreichen die Universität zahlreiche Kondolenzen, etwa von anderen Universitäten. Ein Nachruf von Walter Rüegg (1964), dem damaligen Frankfurter Dekan, hat für Salomon dann große Worten. Dabei fällt jedoch auf, dass er ihn stark judaisierend portraitiert: was Salomon besonders ausgezeichnet habe, wird in Verbindung gebracht mit seiner jüdischen Herkunft. Rüegg benutzt die üblichen Stereotypen der „Rolle eines Außenseiters“, der „fruchtbaren Vermittlertätigkeit“, vom „Weg zu sich selbst über das fremde Gegenbild“, der in die Fremde treibe, von einem „rastlosen“ immer neuen „Aufbruch“ ohne „Heimat“ und von der Vorliebe, „feste Anschauungen

118 Die fünfte Fakultät hätte es „,vorgezogen, wenn er von einer anderen Fakultät aufgenommen worden wäre. Man einigte sich schließlich so, dass er als Mitglied (Emeritus) der Wirtschafts- und Sozialwissenschaftlichen Fakultät geführt wurde; er sollte jedoch nicht an dieser lesen, sondern mit einem unbezahlten Lehrauftrag - an der Philosophischen Fakultät“ (Schefold 2004, 651). Napp-Zinn und Geißendörfer schreiben an den Rektor: da Salomon nicht die Rechte eines Emeritus habe, „wünscht die Fakultät nicht, dass Herr Salomon-Delatour im Vorlesungsverzeichnis der Universität Frankfurt aufgeführt wird“ (Schreiben vom 12.5.1958, UAF, Abt. 4, Nr. 123, Bl. 37).

119 So hat Salomon nach einer Mitteilung von Otthein Rammstedt sich einmal mit Hans Freyer - der in Davos seinerzeit mit einem Cabrio vorgefahren war - in Wiesbaden getroffen und prächtig verstanden.

120 Adorno schreibt als Direktor des Institutes für Sozialforschung an den Dekan der philosophischen Fakultät: „Tatsächlich regt er [Salomon] Arbeiten von Studenten an: nach der bisherigen Regelung müssen dann aber entweder Herr Horkheimer oder ich als Doktorvater auftreten. Ich empfinde das nicht nur Herrn Salomon gegenüber als ein wenig kränkend, sondern meine auch, dass es unbillig ist, einem Gelehrten, der bestimmte Funktionen ausübt, nicht auch die Befugnisse zu erteilen, die sinngemäß mit diesen Funktionen zusammengehen, und ihm, wie man in Amerika sagen würde, den ,credit“ vorzuenthalten, der ihm gebührt“ (UAF, Rektoratsakte; Abt. 134, Adorno an Walter Schlesinger, 6.12.1962; bereits am 13.01.1959 schreibt Adorno dem vorigen Dekan, Hans Sckommodau).

121 Nach O. Rammstedt (siehe 1994, 168); vgl. Rüegg 1964, 627. 
zu sprengen“ - eine Eigenschaft, die Simmel gegenüber Buber als ,jüdisches Prinzip“ bejaht haben soll (Gassen 1958, 223; Köhnke 1996, 176):

„Es scheint mir bezeichnend, dass diese tiefste Schicht seines Herkommens ihren Ausdruck gefunden hat [...] im Vermächtnis seiner Bibliothek an die Bibliothek Jerusalem“ (Rüegg 1964, 629).

Das wirft abschließend die Frage auf, inwiefern Gottfried Salomon als „jüdischer Denker“ betrachtet werden kann.

\section{Ausblick: „Jüdische Soziologie"?}

Stellt der Nachruf Salomon nun zurecht als einen „typisch“ jüdischen Denker hin? Geht die Ablehnung, die Salomon erfahren musste, damit vielleicht auf Antisemitismus zurück? Hierüber lassen sich kaum sichere Aussagen treffen; allerdings finden sich bei Salomon Dokumente, die Aufschluss über sein Selbstbild geben. Er war väterlicherseits jüdischer Abstammung, betrachtete sich dennoch mit einiger Sicherheit als jüdisch, auch wenn er keinen Glauben praktizierte. ${ }^{122}$ Doch hat Salomons jüdische Identität, wie Rüegg nahe legt, wirklich eine Rolle für sein akademisches Selbstverständnis und den Inhalts seines Werkes gespielt? ${ }^{123}$ Und wenn ja, welche?

Vermittelnde geistige Tätigkeiten wurden damals manchmal als eine jüdische „Eigenart“ bezeichnet, etwa von Martin Buber, Werner Sombart oder Theodor Lessing. ${ }^{124}$ Man kann davon ausgehen, dass Salomon

122 Die Enzyklopädia Judaica nennt Salomon aufgrund seiner hugenottischen Mutter „a half-Jew“ (Cahnmann 1971a). Der Vorstand der Israelitischen Gemeinde Frankfurt bittet Salomon 1925 um einen Beitrag zu jüdischen Themen für das Gemeindeblatt (IISH, IIb/1225); um 1932 steht Salomon in Verbindung mit der „Jüdischen Wohlfahrtspflege“ in Frankfurt, von der er sich Daten über deren Finanzlage geben lässt (IISH, IIb/573a).

123 „Es bedürfte einer genaueren Analyse seiner Werke, um zu zeigen, wie sehr diese Schicht [die jüdische, $\mathrm{CH}$ ] implizit die Grundstruktur seiner ursprünglichen dualistische Gesellschaftskonzeption bestimmte“ (Rüegg 1964, 629). Der Dualismus meint Glauben und Politik (627).

124 „Das Judentum kann nicht, wie andere Völker, der Menschheit neue Gegenstände, neue Inhalte geben, [...] es kann ihr vielmehr nur immer neue Einheit für ihre Inhalte geben, immer neue Möglichkeiten der Synthese. Es war religiöse Synthese in den Zeiten der Propheten und des Urchristentums, es war gedankliche Synthese in der Zeit Spinozas, es war gesellschaftliche Synthese in der Zeit des Sozialismus. Zu welcher Synthese bereitet sich heute der Geist des Judentums vor? Vielleicht zu einer, die eine Synthese all jener Synthesen sein wird“ (Buber 1911, 26). „Man sagt gewiss mit Recht - dass die internationale Verbreitung die Juden zum 
das bekannt war. Diese eher rhetorische Figur lässt sich aber bei aller Phantasie kaum auf Salomon anwenden; einmal, weil er selbst diese Verbindung nirgendwo zieht; vor allem aber, weil es sich bei ihm genau umgekehrt verhält. Denn in dem Maße, wie Salomon offen als jüdischer Autor auftritt, hört er auf zu vermitteln. Seine „jüdischen Schriften“ die frühen Aufsätze bei Buber und die Kampfschriften aus dem Pariser Exil - sind engagierte und im Ton kompromisslose Texte, die mit dezidierten Forderungen auftreten. Von Vermittlung ist hier keine Spur. Dort aber, wo Salomon vermittelt, ist er selbst ganz neutral. Oder soll man selbst diese Neutralität noch als etwas Partikulares kennzeichnen, wie dies der junge Löwenthal (nach 1990, 50) bezüglich Karl Marx tat, dem er eine „geistige Aufsaugung des ererbten Judentums zugunsten eines unpersönlichen universalistischen Weltstandpunktes“ unterschob? Eine solch vereinnehmende Lesart müsste an irgendeiner Stelle auf Selbstbeschreibungen zurückgreifen können, will sie nicht äußerlich bleiben.

Salomon war, wie wir gesehen haben, gegenüber völkerpsychologischen Kurzschlüssen skeptisch. Über die Fremdzuschreibung „des“ Juden als „rationalistisch“, die bei Sombart mit der Vermittlungsfähigkeit verbunden wird, ${ }^{125}$ finden sich allerdings einige aufschlussreiche Aussagen. Solche Zuschreibungen träfen nach Salomon gerade nicht das „Wesen“ der Juden, sondern nur eine ihrer Erscheinungen, die eher dazu diente, in der Diaspora das „wahre Leben“ zu verdecken:

„Mit dem Intellekt hat der Jude sich die Macht, ideell und materiell, verschafft, die äußeren Verhältnisse von seiner Seele fernzuhalten und hat im souterrain und jardin secret sein eigentliches Leben gelebt“ (1920a, 249).

Zwar trifft damit auch Salomon solche Zuschreibungen (etwa beim „Streben des Juden nach sozialer Gerechtigkeit“, 1920a, 251), doch sind diese soziologischer als bei der essentialisierenden Völkerpsychologie. Teilweise werden aus der Sozialgeschichte her sogar bestimmte Entwicklungen der jüdischen Geschichte in Frage gestellt. ${ }^{126}$

Dolmetsch befähigte. Aber [...] Bedurfte es dazu nicht erst wieder besonderer, eigener Veranlagung?“ (Sombart 1911, 298, zur „Eigenart“ der Juden als „Organisatoren“ 332). „Das Judentum erhält daher bei den europäischen Philosophen und Soziologen die Sendung, sich zum Träger zu machen solcher ,Werte‘, welche unabhängig sind von Boden und Landschaft und welche den geistigen Adel der einen Vernunftmenschheit begründen. Diese Mittler und Vermittlerrolle entdeckt jede Generation wieder neu“ (Lessing 1926, 124; vgl. Rubinstein 1933, 189).

125 „Der Rationalismus des Juden ist die wichtigste Voraussetzung seiner großen Wandelbarkeit“ (Sombart 1911, 326).

126 „Die jüdische Entwicklung unterscheidet sich von der christlichabendländ-ischen, die denselben Konflikt erbt [zwischen Staat und religi- 
Aus dieser Zurückhaltung heraus lehnt Salomon eine Charakterisierung der modernen Soziologie als ,jüdisch“ deutlich ab, allerdings deutet es gleichzeitig ein jüdisches Selbstverständnis an. Nur lässt Salomon keine zwingende Verbindung zwischen beiden erkennen. Vielleicht darum währte die Mitarbeit an Bubers Zeitschrift nicht lange, denn hier sollte er eben diesen Bogen schlagen. ${ }^{127}$ Interessanterweise jedoch muss Salomon dennoch als ein Spezialist für eben diese Verbindung (Soziologie und Judentum) wahrgenommen worden sein, denn wenig später korrespondiert er mit dem Jüdischen Lexikon über eben dieses Thema. ${ }^{128}$ Der Herausgeber Georg Herlitz lädt ihn ein, mitzutun (Schreiben vom 26.2.1926, IISH, II/573). Gottfried Salomon antwortet am 5.3.1926:

„Eine Soziologie der Juden zu schreiben ist augenblicklich beim dem Stande der Forschung völlig unmöglich. ${ }^{129}$ Ich würde vorschlagen, stattdessen unter dem Titel Soziologie den Beitrag der jüdischen Schriftsteller (Simmel, Oppenheimer, Stein, Nowicov, Worms, Durkheim und Levy Bruhl) zu nehmen.“

Tatsächlich verfasst Salomon dann solche Aufsätze über Max Adler, Ludwig Gumplowicz, Lucien Levy-Bruhl, Franz Oppenheimer und René Worms; allerdings ohne über eine Verbindung zwischen ihrem Judentum und ihren Schriften irgendeine Zeile zu verlieren. ${ }^{130}$ Die Redaktion ergänzt sogar einen Artikel über Salomon selbst (Bd. 4, 59f.). Der von Herlitz vorgeschlagene Artikel über den „Anteil der Juden an Soziologie und Ökonomie“ (Schreiben vom 28.3.1926, IISH, II/573) hingegen kommt nicht zustande. ${ }^{131}$

ösem Gesetz, $\mathrm{CH}$ ], durch die ursprüngliche Schwäche der staatlichen und nationalen Grundlagen. Die theokratische Ordnung kann sich einrichten, weil das jüdische Volk ein Spielball der großen Mächte des vorderen Orients und nicht Meister seines politischen Schicksals ist. In einem gesunden Staat wäre die Gesetzesherrschaft nie durchgedrungen“ (1938b, 13 f.)

127 Buber macht Salomon am 23.4.1920 für die soziologische Kolumne brieflich eine klare Vorgabe: „Heute möchte ich Sie nur zur Vermeidung von Missverständnissen darauf aufmerksam machen, dass in der Rundschau nur solche Schriften zu besprechen sind, die sich ganz oder teilweise, direkt oder indirekt auf das Judentum beziehen oder dies angehen“ (IISH, IIb/178). Nach den beiden Aufsätzen von 1920/21 ist von Salomon nichts mehr erschienen.

128 Zum Jüdischen Lexikon siehe Brenner (2000, 126-141).

129 Unmöglich war es nicht, hat dann doch Ruppin 1931 eine solche verfasst. 1932 sammelt Salomon auch Daten hierzu (IISH, IIb/573b).

130 Herlitz 1927. Salomon hatte sich brieflich erkundigt, etwa am 15.12. 1926 bei Max Adler („Die erste Frage ist: Sind sie noch Jude?“, IISH, IIb/52).

131 Möglicherweise ist der Artikel von Ernst Noam eine Realisierung dessen. Kaznelsons 1959 erschienenes Handbuch wurde bereits 1934 entworfen. 
In dem später vollendeten Alternativprojekt zum Jüdischen Lexikon, der Encyclopaedia Judaica, gibt es einen solchen Aufsatz. Dieser wird interessanterweise vom selben Autor verfasst, der auch den dortigen Eintrag über Salomon beiträgt: von Werner Cahnmann. ${ }^{132}$ Salomon schien diese Assoziation geradezu herauszufordern. Gegen Ende seines Lebens mutmaßte Salomon selbst über eine solche Verbindung, und zwar stellvertretend an seinem Lehrer und Förderer:

„So steht auch hinter Oppenheimers Lehre ein Glaube an die Einheit Gottes und des Menschen, ein jüdischer Glaube, wie er ihm von seinen rabbinischen Vorfahren überliefert war“ (in: Oppenheimer 1964, X f.).

Diese Worte wurden anlässlich der Gedenkfeier für Oppenheimer in Jerusalem gesprochen. Es ist möglich, dass sich Salomon an dieser Stelle mitmeinte, da er lange mit Oppenheimer gearbeitet und einiges von ihm übernommen hat. Andere Stellen bei Salomon jedoch - etwa über Marx - sind solchen Zuordnungen gegenüber weit zurückhaltender. ${ }^{133}$ René Königs Schrift über „Die Juden und die Soziologie“ (1961), welche diese Verbindung zog, lehnte er nach Auskunft Rammstedts $(1998,277)$ ab. Und das letzte Wort zu seinem Doktorvater Simmel, der - wie schon Benjamin (1929) monierte - von seinen Zeitgenossen als „jüdischer Denker“ wahrgenommen wurde, ist: „deutsch“. ${ }^{134}$ Will man dem gerecht werden, kann man Salomon schwerlich in eine „typisch“ jüdische Tradition stellen oder ihn aus dieser deuten, jedenfalls nicht, solange man das nur von außen mit vorgeblich ,jüdischen“ Charakteristika wie einem Denken der „Vermittlung“ oder des „Pluralismus“ rechtfertigt.

132 Dieser hatte bereits im Jahre 1927 Kontakt mit ihm aufgenommen (IISH, IIb/189); siehe jüngst Cahnmann 2005, wo ein Aufsatz Cahnmanns über den „Fremden“ im Sinne Simmels abgedruckt ist.

133 „Es ist sicher verkehrt, in Karl Marx einen jüdischen Propheten zu sehen“ (Salomon 1959, 178). Siehe dazu Henning 2005, 376-399.

134 „Wie in der negativen Theologie ist sein eigentliches Werk [...] mystisch und im Ganzen so deutsch“ (in: Gassen 1958, 292). Ähnlich bereits in der Vorstudie aus den 1940er Jahren: „er war ganz deutsch der Alles-Erklärer [...] Wenn einer so allein denkt, wie es jedem deutschen Philosophen passiert, denn nur in Frankreich ist das Denken sozial, dann muss er diese Isolierung kompensieren, indem er immer dazugehören will“ (in: Rammstedt 1994, 167). Somit stellt er Simmels Eigenart nicht etwa als jüdisch, sondern als deutsch dar, und seine eigene implizit als französisch (vgl. Münch 1986, 551 f.). 
Seine familiäre Herkunft mag für seine Ausgrenzung eine Rolle gespielt haben, doch obwohl er sich mit jüdischen Themen auseinandergesetzt hat, brachte er seine Rolle als Soziologe damit an keiner Stelle explizit in Zusammenhang. ${ }^{135}$ Wie das zu deuten ist, muss offen bleiben. Möglicherweise ist dies eine „liberale“ Einsicht: eine übergeordnete Einheit, die dem Anderen seine Andersheit zugesteht, kann nicht exklusiv sein. ${ }^{136}$ Mag der Soziologie als Person sich verstehen wie er will, sein „vermittelnder“ Standort darf selbst keine Partei sein (auch dann, wenn dieser Standort offensiv vertreten und verteidigt wird). Daher geht die Person Salomons in seiner Rolle als Soziologe nicht auf. Immerhin akzeptierte Salomon die Fremdzuschreibung sehr wohl, wie ein Fragment aus seiner radikalsten Zeit, den 1930er Jahren in Paris, andeutet: „Ich bin, wie mir einmal ein Jesuit sagte, ein Jude im Denken.“137

135 Das erinnert an Norbert Elias, der seine zionistische Jugend bewusst nicht mit seiner Zeit als Soziologe in Verbindung bringt (Hackeschmidt 1997, 157; siehe aber Elias 1990, 159). Brumlik 2006, 264 bringt das bezüglich Sigmund Freuds in Zusammenhang mit Poppers Unterscheidung von „context of discovery“ und „context of justification“. Salomon ist nicht der einzige, der nicht über seine Selbstverortung spricht, was bei ihm vielleicht wirklich mit einer „negativen Theologie“, zumindest dessen Vorbild, zu tun hat (s.o., Fn. 134; vgl. Horkheimer, GS 7, 293 f.; bei dem von „negativ“ allerdings keine Rede sein kann, zu oft sprechen er und Adorno nach 1945 von ihrer jüdischen Prägung, obwohl das Judentum in ihrer Frühzeit so gut wie keine Rolle gespielt hat; Jay 1986, 91; Claussen in Wiehn 1989, 273).

136 Dieser Liberalismus trägt amerikanische Züge; der deutsche Liberalismus hatte exklusive Tendenzen und drängte zur Assimilation (Salecker 1999). Am Ende seines postumen Buches $(1965,691)$ kündigt Salomon nicht zufällig eine Schrift über „Staats- und Staatslehre Amerikas“ an. Bereits 1928 hatte er mit Albion Small die amerikanische Staatsidee als „,a union of disunions, a conciliation of conflicts, a harmony of discords“ benannt (in: Barnes 1927, XXI).

137 Rammstedt 1991, 37. Der Jesuit könnte Erich Pzywara gewesen sein. 